Florida International University

FIU Digital Commons

$12-7-2019$

\title{
The Influence of Employee Engagement on Discretionary Effort and Job Performance in the Cruise Line Customer Contact Center Workplace
}

Stephen B. Rodoquino III

Florida International University, srodo001@fiu.edu

Follow this and additional works at: https://digitalcommons.fiu.edu/etd

Part of the Adult and Continuing Education Commons, Hospitality Administration and Management Commons, and the Human Resources Management Commons

\section{Recommended Citation}

Rodoquino, Stephen B. III, "The Influence of Employee Engagement on Discretionary Effort and Job Performance in the Cruise Line Customer Contact Center Workplace" (2019). FIU Electronic Theses and Dissertations. 4449.

https://digitalcommons.fiu.edu/etd/4449

This work is brought to you for free and open access by the University Graduate School at FIU Digital Commons. It has been accepted for inclusion in FIU Electronic Theses and Dissertations by an authorized administrator of FIU Digital Commons. For more information, please contact dcc@fiu.edu. 


\title{
FLORIDA INTERNATIONAL UNIVERSITY
}

Miami, Florida

\section{THE INFLUENCE OF EMPLOYEE ENGAGEMENT ON DISCRETIONARY EFFORT AND JOB PERFORMANCE IN THE CRUISE LINE CUSTOMER CONTACT CENTER WORKPLACE}

\author{
A dissertation in partial fulfillment of the \\ requirements for the degree of \\ DOCTOR OF EDUCATION
}

in

ADULT EDUCATION/HUMAN RESOURCE DEVELOPMENT

by

Stephen Bernard Rodoquino III

2020 
To: Dean Michael Heithaus

College of Arts, Sciences and Education

This dissertation, written by Stephen Bernard Rodoquino III, and entitled The Influence of Employee Engagement on Discretionary Effort and Job Performance in the Cruise Line Customer Contact Center Workplace, has been approved with respect to its quality of style and content and is referred to you for judgement.

We have read this dissertation and recommend that it be approved.

Teresa Lucas

Melody Whiddon-Willoughby

Jinlin Zhao

Thomas G. Reio Jr., Major Professor

Date of Defense: December 7, 2019

The dissertation of Stephen Bernard Rodoquino III is approved.

Dean Michael Heithaus

College of Arts, Science, and Education

Andres G. Gil

Vice President for Research and Economic Development and Dean of the University Graduate School

Florida International University, 2020 
(C) Copyright 2020 by Stephen Bernard Rodoquino III

All rights reserved. 


\section{DEDICATION}

To my son Michael. You've always inspired me to be my best and go the extra mile. 


\section{ACKNOWLEDGMENTS}

First and foremost, I would like to thank Dr. Thomas G. Reio, Jr., my major professor and dissertation chair. This project would not have come to fruition without the benefit of his superlative knowledge, mentorship, and guidance. His patience and steadiness in being there for consultation and direction when it was most needed was essential to the quality and timely completion of this dissertation. In addition, I would also like to express my appreciation to Teresa Lucas, Melody Whiddon-Willoughby, and Jinlin Zhao who agreed to serve on my committee along with my Chair and provided necessary guidance throughout the duration of the project. Thank you for taking valuable time away from your professional and personal pursuits to contribute your knowledge and expertise to my dissertation process. 


\begin{abstract}
OF THE DISSERTATION
THE INFLUENCE OF EMPLOYEE ENGAGEMENT ON DISCRETIONARY

EFFORT AND JOB PERFORMANCE IN THE CRUISE LINE CUSTOMER

CONTACT CENTER WORKPLACE
\end{abstract}

by

Stephen Bernard Rodoquino III

Florida International University, 2020

Miami, Florida

Professor Thomas G. Reio, Jr., Major Professor

This nonexperimental, correlational study examined the relation among job fit, psychological climate, and employee engagement and discretionary effort and job performance. An Internet-based self-report survey was administered to a sample of 307 cruise line customer contact center reservation agents. The research hypotheses were evaluated using correlational and hierarchical regression analytic procedures.

Job fit and psychological climate were linked positively and significantly with employee engagement and employee engagement accounted for significant variance in both discretionary effort and job performance. In evaluating the discretionary effort conceptual model, after statistically controlling for gender, ethnicity and amount of job experience, the results of the hierarchical regression analysis showed that employees who reported a positive psychological climate and job fit were more engaged and tended to report higher levels of discretionary effort. The results were similar for the job 
performance conceptual model. In both models, demonstrating a large effect size, employee engagement was a powerful predictor of the dependent variables.

The implications for organizational and human resource development theory, research, and practice are pronounced. First, there was strong support for engagement theory in that there was compelling evidence of its predictive validity. Second, decided empirical support was found that linked a positive psychological climate and job fit to not only employee engagement, but also discretionary effort and job performance among call center workers, an understudied group in the travel industry. Third, there was considerable practical utility for the findings because it supports HR/D practitioners' activities that would foster a positive psychological climate and job fit for the sake of building employee engagement, which consequently would promote discretionary effort and job performance. 


\section{TABLE OF CONTENTS}

CHAPTER

PAGE

CHAPTER I.



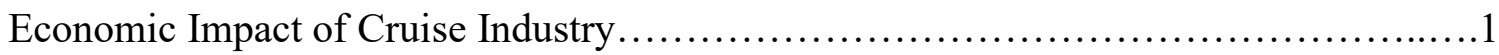

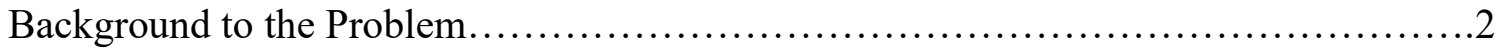



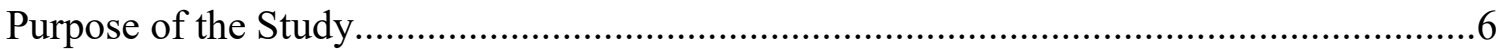

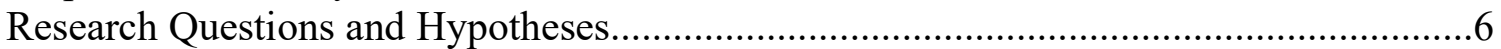

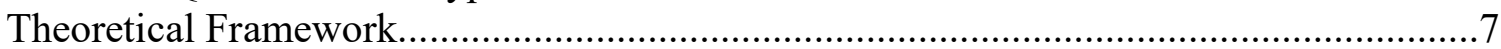

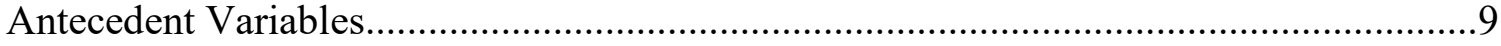

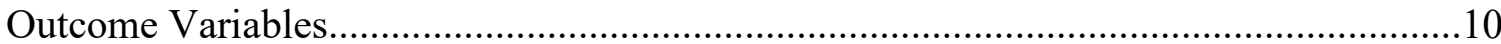

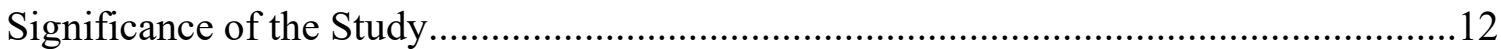

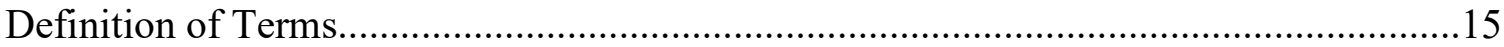

Assumptions and Delimitations of the Study.............................................................18

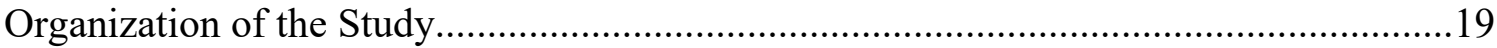

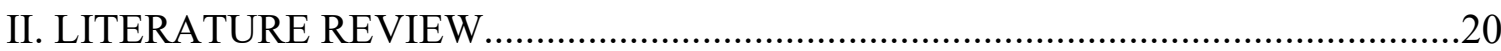

Importance of Employee Engagement for Workers......................................................20

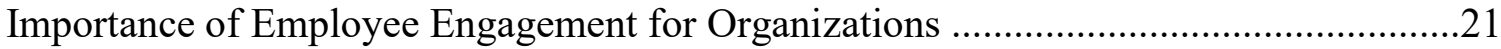

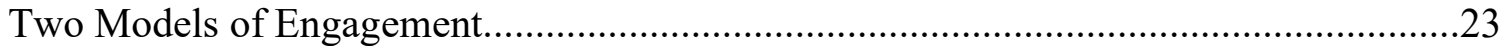



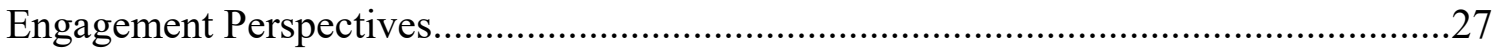

Organizational and Demographic Factors...................................................................32

Empirical Support for Variables of Study ...................................................................35

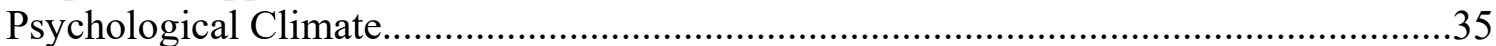



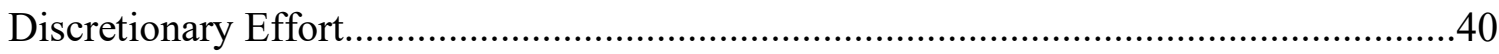

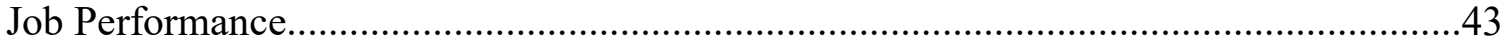

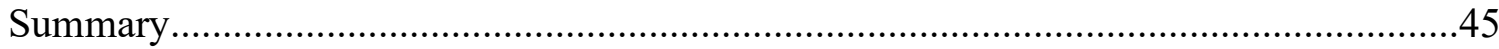

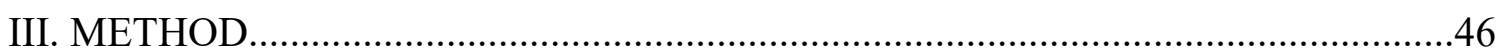

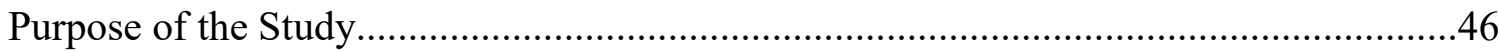





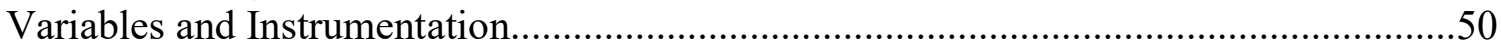





Measurement, Sampling, and Nonresponse Error................................................56

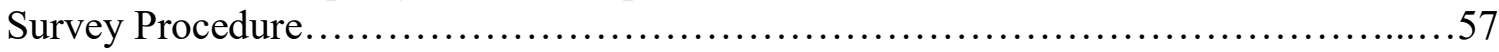

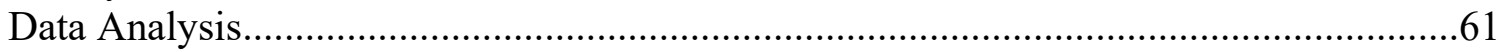








Background of the Sample....................................................................................64

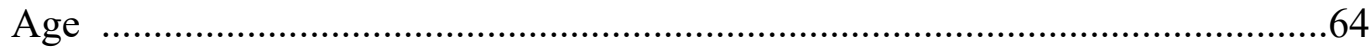

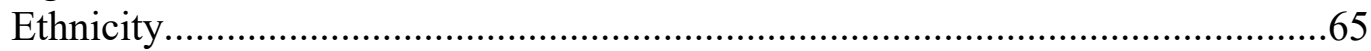



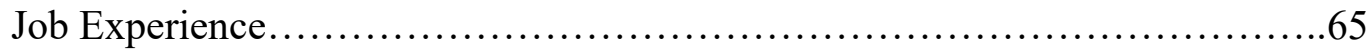

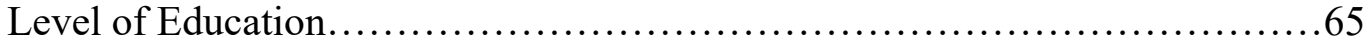

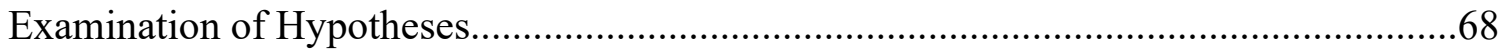

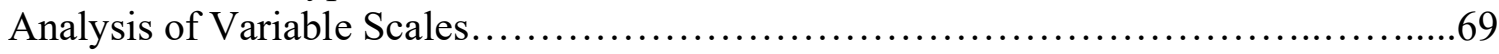

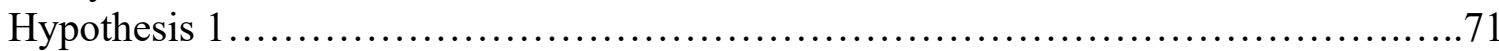

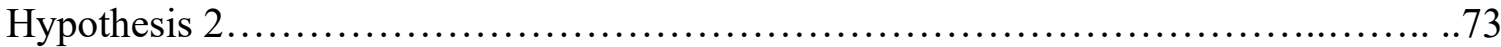

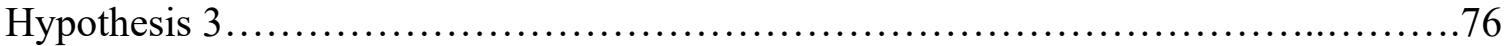

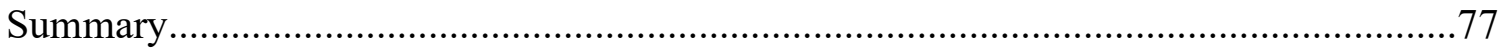

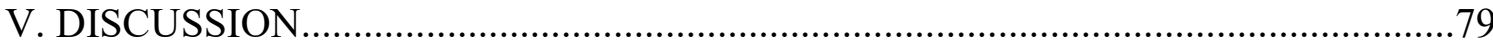



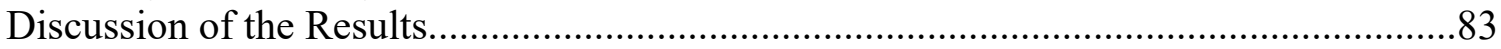



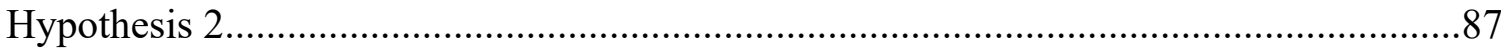

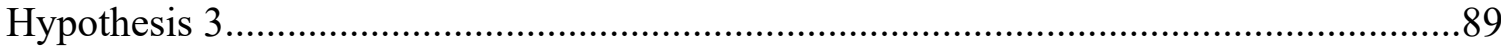

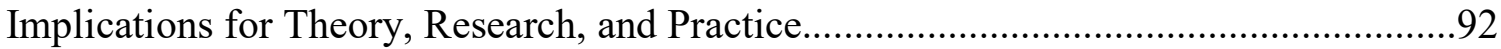



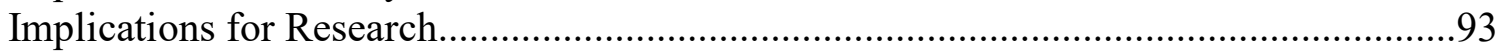

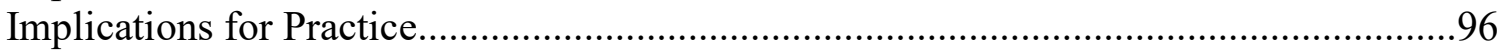

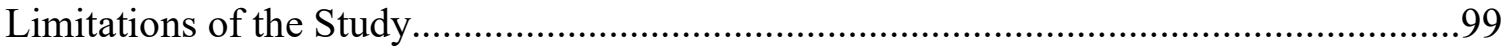

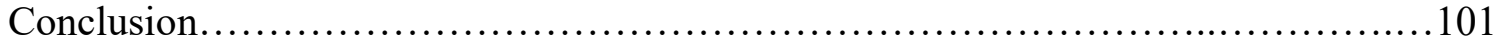

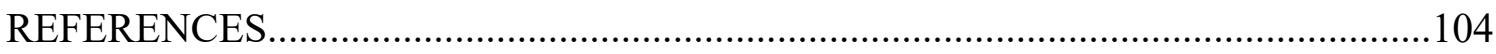

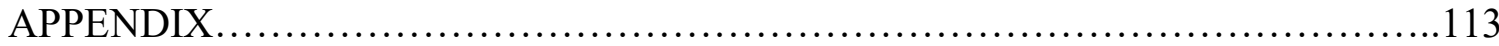

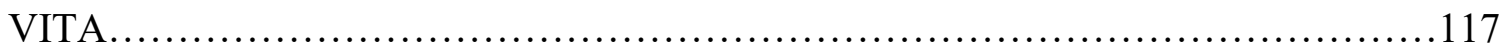




\section{LIST OF TABLES}

TABLE

PAGE

1. Interval-Scheduling Framework for Survey Battery Distribution....................60

2. Demographic Frequency.................................................67

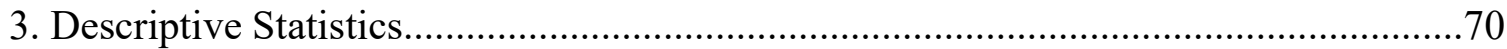

4. Correlations........................................................... 70

5. Summary Hierarchical Regression Analysis with Job Fit and Psychological Climate, Predicting Employee Engagement after Controlling for Demographic Variables.......73

6. Summary Hierarchical Regression Analysis with Job Fit, Psychological Climate, and Employee Engagement Predicting Discretionary Effort after Controlling for Demographic Variables................................................... 75

7. Summary Hierarchical Regression Analysis with Job Fit, Psychological Climate, and Employee Engagement Predicting Job Performance after Controlling for Demographic Variables. 


\section{LIST OF FIGURES}

FIGURE

PAGE

1a. Hypothesized model of job fit and psychological climate, employee engagement,

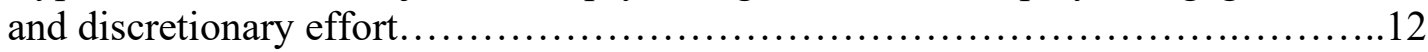

1b. Hypothesized model of job fit and psychological climate, employee engagement,

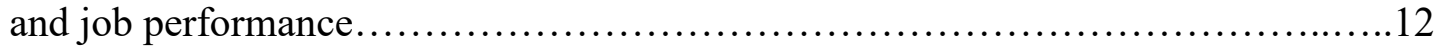




\section{CHAPTER I INTRODUCTION}

Chapter I provides the background to the research problem, the problem statement, purpose of the study, and theoretical framework. Following these initial sections, the significance of the study and definition of terms, as well as assumptions, delimitations, and organization of the study will be presented.

The intent of the research was to determine the importance of employee engagement for cruise line reservation centers located in the United States. There remains a lack of published research pertaining to the employee engagement levels of cruise line call center reservations workers, so the researcher in this study seeks to make a significant contribution to the base of knowledge.

\section{Economic Impact of Cruise Industry}

In addition to providing consumers with high quality vacations, cruising has a tremendous economic impact, both in the United States where many cruise lines are located as well as foreign destinations (Risitano, Sorrentino, \& Quintano, 2017). Risitano et al. (2017) reported that the world cruise tourism volume increased from 6.3 million passengers in 1996 to 24 million in 2015 with the concomitant economic benefit to employees, cruise lines, and ports of call. According to a 2006 study commissioned by the Cruise Lines International Association (CLIA), cruising generated $\$ 35.7$ billion in total annual economic benefit, $\$ 17.6$ billion direct spending, over 348,000 jobs and $\$ 14.7$ billion in total wages for American employees (Gulliksen, 2008). Further, the study 
illustrated that, on average, a single 2,000 passenger cruise ship with 950 crew members produces $\$ 322,700$ in onshore spending in United States homeport cities employed as embarkation points. The revenue comes as the result of tourist expenditure on retail merchandise, dining, and lodging in the vicinity of the ports (Gulliksen, 2008).

In consideration of their economic impact, it is important for these organizations to operate as efficiently and productively as possible for the benefit of their employees and the port cities utilized in cruise operations (Risitano et al., 2017). In particular, it is imperative that cruise lines optimize the proficiency of their reservation call center workers given they are the primary contact point between consumers and the company and are directly responsible for placing passengers onboard the ships. Therefore, understanding the degree employee engagement is linked to discretionary effort and job performance within the cruise line industry is certainly worthy of additional research.

\section{Background to the Problem}

Employee engagement can be defined as an emotional connection with an organization which drives a heightened discretionary effort, reduced turnover and increased productivity, loyalty, and dedication to customer service (Schermerhorn, 2010). Further, Shuck, Adelson, and Reio (2017) suggested that engagement is "reflective of an active psychological state and inclusive of the full spectrum of the immediate work experience" (p. 6).

As much as half of American workers can be categorized as disengaged or only partially engaged (Kim et al., 2013). It has been calculated that the lack of engagement costs businesses as much as $\$ 500$ billion a year in compromised profitability (Saks \& 
Gruman, 2014). Meanwhile, $80 \%$ of engaged employees are relatively productive and less likely to leave their company in the short-term, than those who are classified as disengaged (Hui, Wong, \& Tjosvold, 2007). Howard and Foster (2009) concluded that employee engagement enhances not only the productivity of a firm, but also its public image given the reduction of turnover amongst engaged employees. It has also been discovered that $70 \%$ of job candidates perceive a company with a lower turnover rate as being more desirable to work for while being more employee-focused and financially successful (Stone, Deci, \& Ryan, 2009).

In support of the theory that engagement enhances performance, research by Macey, Schneider, Barbera, and Young (2009) illustrated that, within a sample of 65 organizations in a variety of industries, the top $25 \%$ rated companies on a selected engagement index realized a larger profitability and more than twice the amount of shareholder value than the lowest $25 \%$ of the research sample. Internally, engaged employees also tend to maintain constructive and tranquil working relationships with their managers (Van den Broeck, DeWitte, \& Lens, 2008), while remaining more receptive to ideas of organizational unity and team spirit (Hallberg, 2007).

Additionally, other researchers have lauded engagement as an important driver of workers' behaviors, attitudes, and job results (Bates, 2004; Baumruk, 2004; Kim et al., 2013; Saks \& Gruman, 2014). Moreover, engagement has been linked to increased organizational performance, reduction of turnover, and financial success (Harter, Schmidt, \& Hayes, 2002; Richman, 2006; Shuck et al., 2017). 
Additionally, the element of employee engagement with respect to workers' positions and related job duties may yield a significant influence upon employee satisfaction and ability to maintain an appropriate and productive level of motivation in relation to the performance of their work. It is a generally accepted that the more engaged a worker is with his or her job, the more likely they can continue to perform and stay in congruence with the labor paradigms and supervision prescribed by the organization's management (Shuck et al., 2017). Therefore, the implementation of new management paradigms to enhance engagement is necessary for contemporary organizations to gain a competitive advantage (i.e., efficiency, quality, innovativeness, and customer responsiveness [four building blocks of competitive advantage]; Ferguson \& Reio, 2010) through increased engagement.

The variables of job fit (the degree to which an individual's personality and values fit with their assigned job), psychological climate (employees' interpretation of their work environment in relation to their perception of wellbeing), employee engagement, discretionary effort (the willingness to surpass the minimal results expected to avoid termination), and job performance are factors which can determine the overall competitive capability of a firm (Shuck, Reio, \& Rocco, 2011). Stores of intangible human assets are embedded within firms' personnel, with the challenge of their compensation systems being to positively impact competitive behavior (Offstein, Gnyawali, \& Cobb, 2005). It is essential that we discover the respective linkages among these variables and the resulting outcomes of discretionary effort and overall job performance. The new knowledge would better inform human resource/development 
(HR/D) research and practice (e.g., training and development, coaching and mentoring, and socialization programs),

\section{Statement of the Problem}

While organizations and their human resource departments wish to reap the organizational benefits of enhanced employee engagement and see it as a key to improved performance (Markos, 2010), there remains a lack of academic research to guide human resource and other organizational professionals (e.g., managers) as to how to best achieve it (Byrne, 2015). While still being a relatively new management concept, engagement has quickly become a popular and important target in the formulation of new motivational and productivity paradigms (Macey et al., 2009; Saks \& Gruman, 2014). However, its popularity has outpaced published knowledge concerning the engagement topic; consequently, there is a significant gap in the literature and thus additional research is required to better understand what variables might be associated with effectively creating engagement and what its outcomes might be in organizational settings.

Further, both human resource researchers and practitioners require the guidance and motivation of increased engagement research to collaborate further in terms of effectively understanding and applying the concept. The research and experience can produce improved paradigmatic blueprints for the construction of engagement and performance-producing frameworks and programs. 


\section{Purpose of the Study}

The purpose of the present study was two-fold: first, to investigate the influence

of job fit and psychological climate upon employee engagement. The second purpose was to examine the influence of employee engagement on discretionary effort and job performance.

\section{Research Questions and Hypotheses}

There are two research questions driving this study: (a) What is the correlation between the variables of job fit, psychological climate, and employee engagement? and (b) What is the correlation between employee engagement, discretionary effort, and job performance?

There are three hypotheses which will be tested to evaluate these questions:

H1: There is a positive relationship between job fit, psychological climate, and employee engagement as measured by the results of surveyed study participants.

$\mathrm{H} 2$ : There is a positive relationship between employee engagement and discretionary effort as measured by the results of surveyed study participants.

H3: There is a positive relationship between employee engagement and job performance as measured by the results of surveyed study participants. 


\section{Theoretical Framework}

Gruman and Saks (2011) stated that engagement consists of attentiveness, cognitive alertness, and ardent connectivity of workers to others while enabling the expression of individuality on the job. Kahn (1992), meanwhile, had earlier defined engagement as the ability of employees to maintain a psychological presence while at work while feeling connected, attentive, integrated, and focused on their roles within the organization.

Kahn's (1992) conceptualization and research on engagement laid the groundwork for further study and theoretical application. He initially defined three constructs which define and provoke the development of engagement. Those factors of meaningfulness, availability, and safety are the keys to understanding the bases from which employee engagement originates (Kim et al., 2013; Shuck et al., 2017).

The meaningfulness construct concerns the employees' perceived value of their positions to the organization and to themselves. It provides the individual with a sense of accomplishment and progress toward their self-actualization while being bolstered by feedback received from the organization regarding their value (Jacobs, 2013). The result of greater meaningfulness and supportive feedback is enhanced engagement. A lack of meaningfulness can translate to feelings of employee abandonment by and disengagement from the organization, leading to a greater incidence of underproductivity (Yalabik, Popaitoon, Chowne, \& Rayton, 2013).

The element of availability concerns workers' individual levels of efficacy along with the requisite intellectual and psychological skills to perform the duties of their 
assigned positions. In the absence of possessing the resources and skills relevant to the position, employees must have a perceived access to them to maintain adequate levels of availability (Jacobs, 2013). Therefore, it is essential that the organization ascertains the available necessities of each employee so as to reduce the potentially negative influence on employee engagement levels given the established theoretical relationship (Kahn, 1990) between the variables. These necessities may take the tangible form of equipment, employee support, financial budgeting, or intangibles such as training, feedback, or organizational socialization (Kahn, 1990).

The concept of safety relates to employees' comfort in acting and behaving as they are most comfortable. Put simply, safety concerns people "being themselves" at the workplace without concern for peer rejection or detrimental influence upon their career stability and advancement potential. Safety in this context focuses primarily upon workers' perception of such stability with their career and ease of being within the constraints of their position and the overall realm of the workplace. There are numerous social and psychological elements which combine to exert influence upon this theoretical safety construct including employees' knowledge of company expectations, perception of how the employee's position fits into the organization, and concerns of potential physical, emotional, or psychological harm that might occur in the workplace (Shuck et al., 2017).

The following sections will expand upon what has already been written about the theoretical framework and the antecedent and outcome variables contained within this research study. These variables include job fit, psychological climate, discretionary effort and job performance. 


\section{Antecedent Variables}

The following section presents and describes the antecedent variables utilized in the research. The selected antecedents which will be discussed are job fit and psychological climate.

Job fit. Job fit can be defined as the element of compatibility between employees and the tasks they are required to perform at work (Kristof-Brown, 2016). It is derived from the assumption that specific characteristics of the individual and their job work in collaboration to produce individual outcomes, allowing them a significant level of psychological meaningfulness along with physical and emotional comfort (KristofBrown, 2016). The definition also covers the degree of congruence between employees' needs and the potential for the job to meet those needs, along with the match of workers' skill sets with the demands of the position to which they are assigned. Chen, Yen, and Tsai (2014) have suggested that psychological factors, such as job fit, act as drivers for certain work-related attitudes, including employee engagement, which can affect job performance.

Psychological climate. Psychological climate is defined as a worker's perception of the work environment in which they are engaged. In recent years, it has been the focal point of a significant amount of research within the fields of HRD and organizational psychology. Psychological climate measurement and analysis are designed to evaluate workplace environments as they are cognitively perceived in terms of potential psychological interpretations and meaningfulness to individual employees. In their 
research, Shuck et al. (2011) discovered that psychological climate, along with job fit, were significantly related to employee engagement.

Elements of psychological climate include, among others, relative job importance, clarity of assigned duties, management interaction and support, and group coordination/collaboration levels. Psychological climate is theoretically related to job satisfaction and productivity (Baltes, 2001). Harter et al. (2002) found that these variables significantly relate to the perception of an employee's experience of work and affect the development of employee engagement. Additionally, psychological climate provokes feelings of meaningfulness in employee work assignments and augments employee engagement levels through an enhancement of perceived management and group support, role clarity, and job meaningfulness (Kahn, 1990).

\section{Outcome Variables}

Discretionary effort. Discretionary effort can be defined as the amount of effort organizational employees could exert, if willing, in excess of the minimum required (Shuck et al., 2011). Management performance programs typically encourage employees to attain only minimal standards to maintain the continuity of their employment and avoid demotion or termination. These organizations practice negative reinforcement and manage by exception, imposing penalties for employee performance only on occasions where it recedes below a stated minimum. While such a method promotes instantaneous response from employees who wish to stay at the stated minimum to avoid a threat to their job status, it does not necessarily motivate them to go beyond the perceived expectations of performance due to the absence of emphasis on outstanding levels of 
achievement (Daniels, 2013). Discretionary effort has been positively associated with performance and has also been linked to increased productivity and profit generation and is thought to be a behavioral outcome variable of an engaged employee (Reno, 2007).

Job performance. Job performance, within the context of the present study, is defined as the proficiency and accuracy with which the prescribed duties of a particular position are achieved by employees through specific actions and behaviors (Rotundo \& Sackett, 2002). The results of performance can be measured according to specifically designed scales and assessments.

Performance carries a high degree of importance because it primarily determines disciplinary and reward actions of management. In a customer service environment, job performance includes the tangible delivery of services as well as intangible facets such as acceptable displays of emotions, effective inter-personal relationships between employees, and other behaviors which are deemed relevant to the assigned duties of the position (Bowen, Siehl, \& Schneider, 1989). The proposed models which includes the aforementioned antecedents, engagement, and outcomes are illustrated below. 
Figure 1a. Hypothesized model of job fit and psychological climate, employee engagement, and discretionary effort.

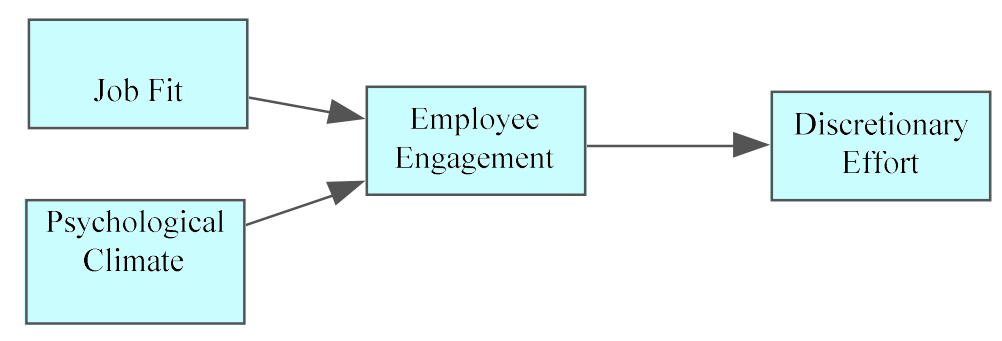

Figure $1 b$. Hypothesized model of job fit and psychological climate, employee engagement, and job performance.

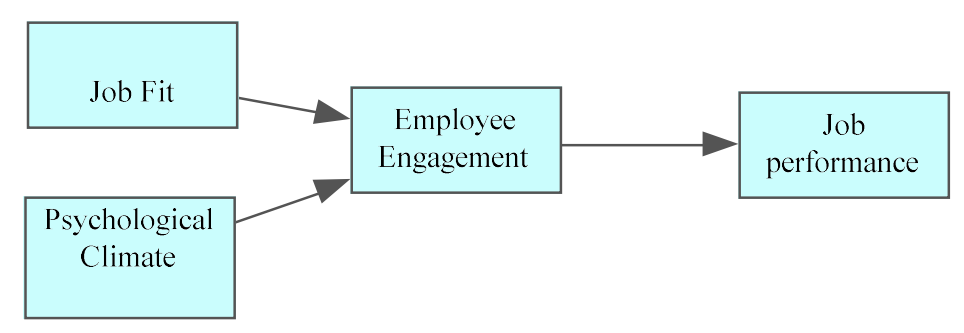

\section{Significance of the Study}

While the concept of engagement has captured the imagination of HR/D researchers and practitioners and management professionals over the past two decades, it remains one in need of additional empirical research and understanding (Ristano et al., 2017; Saks \& Gruman, 2014; Shuck et al., 2017). There persists a significant level of controversy about its meaning and theoretical underpinnings (Kim et al., 2013; Shuck et 
al., 2017). In addition, a widening fissure has developed between researchers who view engagement as a psychological state of mind and organizational professionals who approach engagement as a concept of workforce strategy (Truss, Delbridge, Alfes, Shantz, \& Soane, 2014).

Therefore, research must continue to develop and refine the employee engagement model. The objective is to capture the comprehensive influence the variables presented in the model yields on employee performance and discover how to more efficiently cultivate the psychological state of engagement within workers' minds. The goal may be achieved through researching the possible linkages among variables presented in the aforementioned model and applying what was learned to create an optimally engaged workforce (Mone \& London, 2010).

As new research continues to be published, organizations seek to find a practical "how-to" guide which can effectively define engagement for their human resource/development (HR/D) departments and provide a research-supported means of utilizing it to promote employee effort and performance. Firms are seeking to capitalize on the relatively new, popular phenomenon and realize the benefits of the enhanced organizational performance and financial return that recent research professes it provides.

There is a great volume of research required to comprehend what specifically drives engagement and what the results from it might be across a variety of contexts, theoretical frameworks, and perceived variations of engagement. The research must go beyond elementary variations in attitude, ability, and mood in relation to work and supervision. Further, collaboration between HR/D researchers and organizational 
practitioners is essential to bridge the gap between their philosophical differences and achieve productive solutions in relation to "engagement management." Because there are no established guarantees as to how and when employees will fully engage, a large volume of research is required to better facilitate engagement's successful application to various situational environments (Byrne, 2015).

The antecedents and outcomes included in the study may extend the epistemology of currently published research on engagement providing a continuation of theory building in relation to the variables utilized. The unique blend of variables tested in the study and the model within which they are incorporated attempt to provide a novel view of their theoretical influence, while offering insight into their linkages to each other.

The dependent variables of discretionary effort and job performance, theoretically related to the independent variable of employee engagement, are highlighted to provide a practical application of the research to organizational management practice. This may provide organizations with a theoretical underpinning through which they may manipulate elements of job fit, and psychological atmosphere to attain specifically targeted job performance results. The methods of implementation and intervention may include alterations to recruitment and training paradigms, supplemental reward programs, or promotion of new organizational socialization techniques to accentuate the positive relationships between engagement and discretionary effort and job performance.

New research may offer organizational professionals a guide to greater success within their particular realm of the industry. It may further enlighten them to the specific and most significant drivers of engagement while providing them a research-based 
awareness of engagement's importance to operational efficiency and long-term success of both employees and the firm. The present study also attempts to provide practitioners with a greater depth of understanding regarding the relationships between variables, providing them the ability to interpret and manipulate the variables in their respective workplaces to realize desired performance results.

Essential to the efficient sharing of research findings and newly proposed paradigms of engagement proliferation is the construction of effective communication channels within organizations. Enhanced communication is an essential element to organizational socialization, which in turn functions as a support mechanism for psychological climate and the precipitate of increased engagement levels (Walker, 2012).

\section{Definitions of Terms}

Antecedent variable. A variable within a research study which precedes other variables or consequences. It occurs prior to a response but may not necessarily have a causal effect (Pam, 2016). Antecedents discussed in the study include psychological climate, job fit, and extrinsic rewards. Because this is a nonexperimental study, causality cannot be assumed.

Availability. A job-related psychological factor which is associated with employee access to intellectual, skill, and financial resources (Jacobs, 2013).

Discretionary effort. The effort workers will provide above the established minimum required, if they so choose (Daniels, 2013). 
Employee disengagement. An emotional distance between the worker and organization which leads to disenchantment, reduced productivity, and intention to turnover (Blank, 2012).

Employee engagement. An emotional feeling of attachment to and absorption with one's work that is linked to heightened discretionary effort, reduced turnover, and increased productivity, loyalty, and dedication to customer service (Schermerhorn, 2010).

Feedback. A response or update on workers' progress or opinions. It may be provided by a supervisor but may also come from coworkers in the same position. Likewise, managers may also be provided feedback by management peers, as well as employees, as a way of monitoring performance and sharing ideas for greater acceptability or improvement of the organization.

Job fit. Job fit can be defined as the element of compatibility between employees and the tasks they are required to perform at work (Kristof-Brown, 2016). It is founded on the assumption that specific characteristics of the individual and their job work in collaboration to produce individual outcomes, allowing them a significant level of psychological meaningfulness along with physical and emotional comfort

Job meaningfulness. The meaningfulness construct defines the employees' perceived value of their positions to the organization and to themselves. It provides the individual with a sense of accomplishment and progress toward their self-actualization while being bolstered by feedback received from the organization regarding their value (Jacobs, 2013). 
Job performance. The measurement of work results from employees, employee groups, or the organization as a whole as compared to benchmark goals and objectives designed to produce effective productivity and financial result for a firm (Mone \& London, 2010).

Management. The team of supervisory personnel within an organization. It is usually organized into levels which correspond to and coordinate activities and strategy (Albrecht, 2012).

Organization. A group of individuals who combine to work together toward common objectives according to methods and strategies determined by ownership and its managerial personnel in cooperation with employees (Hauser, 2014).

Organizational socialization. The process by which an employee becomes personally acclimated to and affiliated with an organization and its individual employees on a personal level which transcends the assigned performance of duties within a particular position (Reio \& Callahan, 2004). It is a preliminary factor in the formation of employees' organizational personalities and a provocateur of employee engagement.

Outcome variable. The results which emanate from the influences of antecedent, independent variables upon the selected dependent variables. There may or may not be a causal relationship between the dependent variables and outcome variables, but the outcomes always occur after the dependent variables have been influenced (Lloyd, 2008).

Psychological climate. Psychological climate is defined as a worker's perception of the work environment in which they are engaged (Garner \& Hunter, 2013). It has been 
the subject of a significant amount of research within the academic genre of organizational psychology.

Psychological safety. Psychological safety concerns people "being themselves" at the workplace without concern for peer rejection or detrimental influence upon their career stability and advancement potential. It focuses primarily upon workers' perception of such stability with their career and ease of being within the constraints of their position and the overall realm of the workplace (Kahn, 1990).

Workforce. The amalgamation of all labor participants within a particular company department, organization, industry, or society.

\section{Assumptions and Delimitations of the Study}

\section{Assumptions}

In the present study, the assumptions include: (a) the work environment provides every employee the basic elements necessary for them to become engaged in their work; (b) employees are in a psychologically stable and predictable state of mind to be influenced by their organizations; (c) employee engagement is a universally applicable concept for employees of all sex, age, and ethnic groups; and (d) workers have similar needs and motivations for working.

\section{Delimitations}

Although it would be ideal to investigate the hypothesized relationships among the research variables (job fit, psychological climate, employee engagement, 
discretionary effort, and job performance) with all workers, this research will be limited to cruise line workers in South Florida.

\section{Organization of the Study}

Chapter I illustrates the background of the problem, the statement of the problem, the purpose statement, and theoretical framework of the study. In addition, the significance of the study, definitions of terms utilized within the text, and relevant assumptions and delimitations are proposed and explained.

Chapter II follows with a presentation of a review of the literature which will inform and support the research study. Chapter III then proceeds to outline and detail the research method to be utilized in the performance of the research before Chapter IV presents the pertinent findings of the study. Finally, Chapter V includes a discussion of the research discoveries, theoretical implications, as well as the implications for future HR/D research and practice. 


\section{CHAPTER II}

\section{LITERATURE REVIEW}

The following section provides a comprehensive review of employee engagement literature relevant to the proposed research models. First, the significance of employee engagement in the context of employees in the workplace will be examined. The Kahn (1990) model, which serves as the origination point of employee engagement research, will be illustrated and discussed in detail. Further, the practical influence of job fit and psychological climate will be presented and their respective relationships to employee engagement explained. Finally, the association of employee engagement to the outcome variables of discretionary effort and job performance will be investigated. The research provided will justify the variables' inclusion in the engagement models offered in the study.

\section{Importance of Employee Engagement for Workers}

Prior to delving into prior research relating to the relationships between the variables included in the research model, the significance of employee engagement from both an individual employee and comprehensive organizational standpoint will be examined. Engagement has been shown to exert a positive influence on employees' attitudes and perceptions (Shuck et al., 2011). Kahn (1992) presented support that engagement's positive influence on workers comes as a result of feeling free to be their complete and genuine selves in the workplace, while possessing an intrinsically motivated bond with their assigned duties. The resulting level of comfort leads to an 
enhanced sense of commitment and job satisfaction as they tend to acquire an enhanced sense of ownership and meaningfulness about their jobs (Jacobs, 2013).

The sense of bonding between employee and organization can promote a productive mutual relationship. It may yield positive results for the individual both in the workplace and in their personal lives. For example, a study by Demerouti, Cropanzano, Bakker, and Leiter (2010) illustrated a beneficial, positive relationship between engagement evaluation scores and overall health and well-being.

\section{Importance of Employee Engagement for Organizations}

Increasing the level of individual worker engagement can yield significant benefits for the organizations where they are employed. Previous research has discovered that an engaged worker is a more productive worker (Shuck et al., 2011; Reio \& SandersReio, 2011). Because elevated engagement produces a more committed and satisfied employee, studies have shown that it can result in a more concerted overall labor effort as well as increased levels of job performance (Bakker \& Leiter, 2010).

Because engagement has been shown to be transferable (Demerouti et al., 2010), the highly engaged employee may act as a motivator for others around him or her to become engaged and productive in their assignments. Therefore, increasing the engagement level of a single employee can produce a productive impact on others who work with them. Herein lies the driver of the urgency with which human resource professionals are approaching employee engagement. Indeed, engagement can stand as a highly desirable and beneficial "virus" which can spread rapidly throughout an organization, creating a more productive environment. 
Further, employee engagement has been shown to reduce employee turnover (Shuck, Twyford, Reio, \& Shuck, 2014) and raise levels of attendance (Breevaart, Bakker, \& Demerouti, 2014). With workers being present more often, organizations may reap the benefits of enhanced employee skills, collaborative effort, and productivity (Byrne, 2015).

Viewing its overall effects, engagement can provide a competitive advantage within of an organization. By having workers who are present, satisfied with their roles, and eager to cooperate with others in their relevant work groups, the entire organization can realize elevated levels of productivity and viability (Breevaart et al., 2014). In his research on engagement, Shuck (2010) also concluded that engagement is a highly valuable element within organizations. He discovered that engaged employees are significantly less absent and choose to remain with the firm for a longer period, while exhibiting increased productivity, attaining higher ratings on customer satisfaction surveys, and experiencing a reduced number of on-the-job accidents. In summation, Shuck (2010) noted that these positive influences tend to equate to higher organizational efficiency and profitability. The resulting challenge for firms' human resource departments is to introduce and instill engagement facilitating policies and procedures which will strengthen the fiber of the individual employees and their colleagues while producing improved bottom-line results for the entire organization. 


\section{Two Models of Engagement}

Two models of engagement, Kahn's (1990) and Harter et al.'s (2002) seminal work will be discussed, compared, and integrated. The merits and drawbacks of each will be discussed.

\section{Kahn's Research}

Kahn, being the acclaimed pioneer of the modern employee engagement theory, formulated his need-satisfying approach to disseminate and define the components of what he believed were the effective drivers and outcomes for the independent element of engagement. He constructed a theoretical framework which illustrated the esoteric underpinnings of what it means to be an engaged employee. Kahn (1990) defined engagement using the three conceptual psychological components of safety, meaningfulness and availability as antecedents following the Hackman and Oldham (1976) job characteristics model, which examined the influence of work upon employee behavior and disposition. The fulfillment of each of these components provided the psychological basis for what could be defined as an "engaged" employee.

In support of Kahn's research, a study conducted by May, Gilson, and Harter (2004) confirmed the relationship between Kahn's proposed antecedents and employee engagement using path analysis. In addition, the personal features of job fit and job enrichment were found to act as drivers for the psychological element of meaningfulness, which completely mediated the relationship between job fit and enrichment (Jacobs, 2013). 
Meaningfulness was described by Kahn (1990) as an effective and enduring biproduct of an employee's psychological investment in their job duties, while describing the conceptual element of safety as the ability to act as themselves without fear of reprisal in terms of negative consequence relative to job status and image. Meanwhile, availability was the degree to which a worker was being provided the perceived emotional, psychological, and material resource to perform in satisfactory fashion according to organizational expectations (Kahn, 1990).

While Kahn's research identified employee engagement as an independently influential variable, it does not continue forward in describing prospective outcomes. $\mathrm{He}$ presents engagement as a precipitate of various psychological factors but fails to examine what individual and organizational results are produced by it. Therefore, it is necessary to examine the research which followed Kahn's to discover the psychological and practical results of employee engagement levels.

\section{Harter, Schmidt, and Hayes's (2012) Research}

Kahn's research and acclaim provoked others to consider and continue defining the concept of employee engagement. Research conducted by Harter et al. (2002) provided the basis for another method of engagement evaluation. Harter and his associates conducted a meta-analysis of 7,939 individual businesses across a range of differing industries to gain a more comprehensive examination of employee engagement in the workplace. The authors defined employee engagement as the individual's involvement and satisfaction with and enthusiasm for work while seeking to examine the relationships between changes in management practice paradigms, increases in workers' 
satisfaction, and outcomes at the business-unit level. Their meta-analysis differed from other studies in that, instead of focusing on relatively homogenous business units within similar industries, it transcended industry and organizational boundaries to gain a broader engagement perspective.

The study hypothesized that employee satisfaction and engagement at the business-unit level would be positively correlated with the outcomes of productivity, employee retention, employee safety, and bottom-line profits. They also postulated that these correlations would remain consistent across business units of a variety of organizations without significant fluctuation.

The researchers utilized the Gallup Workplace Audit (GWA; The Gallup Organization, 1992-1999), an instrument which was extrapolated from previous research on employee satisfaction, management practices, motivation, and business-unit efficacy. The GWA was comprised of 13 items. One item designed to measure overall satisfaction in addition to 12 items others that evaluated employee impressions of the workplace characteristics akin to the psychological climate of the organization (Harter et al., 2002). In the study by Harter et al.'s (2002) measure demonstrated a Cronbach's alpha of .91 across 4,172 business units.

The results of the meta-analysis showed that employee engagement positively impacted a variety of business outcomes. Comparing the differences between the highest and lowest quartiles of engagement scores of business units within organizations, it was found that productivity $(+\$ 162,000)$, customer satisfaction loyalty $(+2.9 \%)$, and profitability $(+2.0 \%)$ were all positively influenced by increased levels of employee 
engagement (Harter et al., 2002). Additionally, business units scoring in the top quartile

of engagement had, on average, monthly revenues which were from $\$ 80,000$ to $\$ 120,000$ greater than the lowest quartile. The enhanced productivity translates to an approximate $\$ 1$ million increase in added annual revenue (Harter et al.).

These statistics indicate that employee engagement is related to positive business outcomes to a degree that it should be considered important to management of organizations and that these correlations may be universally applicable to companies in all industries (Harter et al., 2002). While the meta-analysis conducted by Harter et al. (2002) encapsulates the findings of engagement literature, it does not provide a comprehensive perspective of engagement from antecedents to outcomes nor does it describe the contextual backgrounds of the studies utilized. Thus, the research provides for a generalized overview, but does not consider demographics and organizational genre.

\section{Combining Engagement Models}

To provide a comprehensive conceptual model of engagement, the two engagement models described and analyzed above can be selectively combined. While Kahn's work initially theorized the underpinning framework of engagement, it was left for researchers who proceeded him to build upon his work and formulate practical methods of measuring and employing engagement in the workplace.

Kahn conceptualized the three conceptual psychological components of safety, meaningfulness, and availability as antecedents of employee engagement. His illustration of their linkages to the theoretical element of engagement provided researchers with the 
framework to examine the relationships of these variables, as well as other possible antecedents and outcomes of engagement.

The work of Harter et al. (2002) provides a means of analyzing the outcomes which result from the antecedents that Kahn first described as well as the employee engagement product that results from the presence of the antecedents. Their research went a few steps further in defining the results and studying the practical applications and effects of changes in organizational management paradigms on levels of employee satisfaction, retention, and performance. The analysis was followed by the presentation of a testing instrument, the Gallup Workplace Audit.

\section{Engagement Perspectives}

The following section demonstrates implementation and importance of employee engagement in a variety of organizational hospitality contexts. It examines published literature that details various drivers and respective values in work settings that positively affect the production and influence of engagement. While the focus of the research data collection is on the cruise line segment within the broader hospitality field, a perspective of how engagement facilitation in other sectors of hospitality provides a useful perspective that expands the epistemology of employee engagement.

\section{Engagement in Restaurants}

Carter and Baghurst (2014) examined servant leadership and employee engagement in relation to restaurant employees. Servant leadership combines the elements of customer service, ethics, and engagement to promote a culture that aspires to 
unite management and employees in the pursuit of organizational goals without authoritative or positional power. The study discovered that servant leadership positively influences both employee engagement and loyalty of workers.

Servant leadership requires that leaders not be primarily motivated by selfinterest or power (Arkin, 2009), while promoting trust, commitment, loyalty, and growth within their employees (Rofcanin \& Mehtap, 2010). With a focus on fulfilling the needs of others, managers view the development and growth of their employees as a priority, while front-line employees are dedicated to the fulfillment of the customer. Servant leadership has historically been commonly seen in religious and other non-profit organizations, yet it has gained momentum in labor-intensive environments such as restaurants in recent years. Here, the leaders attempt to act as "servants" rather than supervisors in prioritizing employee development and assisting them in the attainment of their goals instead of focusing on personal gain (Greenleaf, 1998).

In the study by Carter and Baghurst (2014), the Celebration Restaurant chain locaed in Dallas, Texas incorporated servant leadership into their new-hire training as well as their monthly unit discussion groups. The result was that employees felt an elevated level of bonding with the organization and that their opinions were valued. The employees also felt obligated to provide efficient customer service and act in the best interests of the organization, while concurrently exhibiting enhanced levels of employee engagement. With their managers being interested in their personal success, employees were influenced to thrive and were inclined to remain with the organization. 
The servant leadership used in the context of the study relied heavily on increased engagement levels to promote organizational success. It sought to build through the fulfillment of employees' intrinsic needs instead of extrinsic rewards. Additionally, it minimized the importance of managers' personal objectives. Thus, there existed a significant linkage and overlap of servant leadership and engagement. It can be accurately postulated that, in non-profit organizations and labor-intensive environments such as restaurants, management must rely heavily upon intrinsic motivators because extrinsic rewards and personal gain may be less available than in other types of businesses.

\section{Engagement in the Airline Industry}

An example of employee engagement in the airline industry can be sampled from the innovative management practices in effect at Southwest Airlines. An established low-cost carrier, Southwest has designed ways of promoting and benefitting from inflight procedures which build a sense of ownership and psychological safety to increase efficiency, employee satisfaction, and quality customer service.

Thomas (2015) describes an engagement-building agenda that involved assisting flight crews in maintaining a strategic focus in all facets of flight operations, permitting innovation and risk taking as a means of empowering crew members, capitalizing on opportunities as they arise, and maintaining flexibility in relation to products and services as client needs demand. In addition, Southwest promoted a team concept where all employees are expected to support each other and, as needs arise, assist in completing tasks which are not ordinarily within their job descriptions for the sake of efficiency. It 
included having crew members assist in cleaning planes when the necessity arose to maintain flight punctuality (Smith, 2004).

The airline crew members were also encouraged to inject humor into routine preflight and in-flight procedures. The program included flight attendants "rapping" the preflight safety instructions and conducting seemingly inane, yet entertaining contests such as awarding a free air ticket to the first passenger who can prove they have holes in their socks (Smith, 2004). These types of activities served to alleviate job stress for crew members while providing a lighter atmosphere for passengers. By allowing crew members to use their imaginations, be themselves, and implement creative ideas to improve the in-flight environment, individual psychological safety levels increase and engagement may be further improved (Kahn, 1990). As Shuck and Reio (2013) discovered, increased levels of engagement translate into greater feelings of job accomplishment and psychological well-being, providing for a more satisfied employee.

\section{Engagement in Cruise Lines}

A study by Radic (2015) examined levels of employee engagement of cruise ship crew members. The research involved surveying 246 crew members and officers on a contemporary cruise ship during the course of a voyage. Factors of engagement including capacity to engage, communication and progress, feelings of freedom and trust, and engaged behavior were examined and analyzed.

Radic (2015) determined that there was potential for cruise lines to enhance employee engagement within their ship crews by boosting levels of the communication and progress, engaged behavior, and capacity to engage factors. These findings have 
important implications for cruise tourism theory and practice. In doing so, cruise lines not only improve engagement levels of their employees but can also realize the outcomes of discretionary effort and job performance that are essential to favorable fiscal results in the microcosm of the organization; that is, the cruise ship. Concomitantly, an engaged workforce equates to an effective provision of customer service and increased passenger satisfaction (Garcia-Buades, Martinez-Tur, Ortiz-Bonnin, \& Peiro, 2016; Heymann, 2015), which may serve as a driver of cruise line success.

\section{Engagement in Hotels}

With the hotel industry in India experiencing a considerable rate of growth, the ITC Maurya hotel firm decided to evaluate their human resources practices and discover potential areas of improvement (Anand, 2011). They surveyed their employees to ascertain their levels of satisfaction and engagement. Because the general rate of turnover within the hospitality industry ranges from $78 \%$ to $95 \%$ (Anand, 2011), it is urgent that firms efficaciously implement programs to promote satisfaction and engagement within their respective workforces.

To elevate engagement levels, ITC began utilizing a monthly newsletter, the Maurya Gazette, to inform workers of hotel events and company news while featuring "departments of the month" and "employees of the month." Additionally, Good Morning Maurya was published on a daily basis to inform employees about day-to-day activities such as yoga classes, birthdays, lunch menus, service awards and open forums (Anand, 2011). By facilitating communication and collaboration between employees, company employee engagement levels were elevated (Kang \& Sung, 2017). 
Additionally, ITC utilized a performance appraisal process that evaluated employee behavior within the hotel. The appraisal included five selected categorical parameters designed to address esoteric requirements of the hotel operations environment: 1) Customer perspective, 2) Financial perspective, 3) Internal perspective, 4) Employees perspective, and 5) Social perspective. The appraisal was designed to improve performance through the provision of practical feedback and assisted in aligning management expectations with employees' personal objectives. The process of appraisal and revelation of feedback has been shown to enhance engagement levels in workers (Anand, 2011).

\section{Organizational and Demographic Factors}

A study of Jamaican hotels by Rigg, Sydnor, Nicely, and Day (2014) evaluated the influence of organizational and demographic factors on employee engagement. Among the factors evaluated were gender, age, educational level, and departmental positioning within the firm. Each of these factors are illustrated and analyzed in the following section.

\section{Gender}

According to Pitt-Catsouphes and Matz-Costa (2008), engagement was also influenced by gender, age, family income, marital status, and race. In their research, female employees tended to be more engaged in their work than male employees. However, in contrast, Schaufeli and Bakker (2003) found men to be more absorbed and vigorous at work than their female counterparts. In addition, two other studies concerning gender and engagement in the hospitality field by Kim, Shin, and Swanger 
(2009) and Zeng, Zhou, and Han (2009) revealed no significant relationship between gender and engagement (Rigg et al., 2014). Thus, it can be speculated that the correlation between gender and engagement may be moderated by other environmental, organizational, and demographic factors of study participants.

\section{Age}

Published research on the relationship between age and employee engagement by the BlessingWhite consulting firm has generally found that older employees tended to exhibit higher levels of engagement than their younger counterparts on a global scale. More specifically, Zeng et al. (2009) revealed that employees between 31 and 40 years of age exhibited higher engagement levels than both younger and older groups. Conversely, a study of hotel managers by Burke, Koyuncu, Jing, and Fiksenbaum (2009) did not support the theory of age being an influential antecedent of employee engagement (Rigg, 2014). It was revealed in their study that age had no substantial relationship with employee engagement. Considering that the previously referenced studies included employees of all organizational levels, while that of Burke et al. (2009) focused on managers, the research lends support to the theorization of organizational departmental level and position as potential moderators of the effect of age on engagement levels.

\section{Education}

Burke et al. (2009) found no significant relationship between education and engagement in their study focusing on hotel employees. On the other hand, Zeng et al. (2009) described graduate students as possessing lower engagement levels than their less educated coworkers. It may be that the graduate students, seeing their positions as being 
relatively temporary and part-time, may not be as engaged as their coworkers who have more permanent, full-time positions. Future research needs to tease out engagement in the sense of permanent versus temporary workers.

\section{Department}

BlessingWhite has also documented that employees who worked closest to the customer relations, strategy, and decision-making departments showed the highest levels of employee engagement within organizations. Thus, sales and human resource department employees displayed the most engagement in nearly all global regions, while workers in departments such as finance and accounting demonstrated the least. Within the hospitality industry, those who worked closest to the customers in hotels tended to exhibit higher levels of employee engagement than those in areas that did not interface with guests (Rigg et al., 2014). The inference provided by the research is that the closer employees are to the hands-on provision of customer service, the greater their engagement levels. Therein lies the question of whether the degree of proximity to customers provokes employee engagement levels or if, simply, the presence of elevated engagement levels within employees is a necessity for them to remain in customer service positions.

\section{Job Experience}

Engagement research regarding job experience is fleeting. When examining the engagement literature, engagement is thought of as an emotional experience (Kahn, 1990). Notwithstanding, little research has been conducted that investigates the amount of job experience; that is, years of workplace experience. Bandura (1993) demonstrated 
that staff longevity (years of experience in teaching profession) had a pronounced negative effect on the collective efficacy (teacher's and staff's beliefs in their school's capability as a whole to impact student performance) of the teachers and staff of the schools being examined. It may be that in certain professions (e.g., nursing, customer service), as years of experience increase, engagement may be impacted negatively. Such an intriguing idea warrants inclusion in the research.

\section{Empirical Support for Variables of Study}

\section{Psychological Climate}

Dollard (2010) described how psychosocial safety was a significant driver of employee engagement. A model was constructed of psychosocial safety climate (PSC) to define the roots of job demands, psychological health, and employee engagement. The PSC combines psychological safety and the safety climate, both of which serve to affect employees' psychological health. Workers who experience a team environment that is psychologically safe are free to engage in risk-taking that is necessary for learning (Reio, 2007). Meanwhile, organizational climate refers to a common perception of company policy and procedure. The combination of the psychological safety and organizational climate factors produces the construct of psychosocial safety, which relates to a liberation from psychological and social risk in the workplace.

Dollard (2010) predicted that PSC, or the policies and practices which secure worker safety and psychological well-being, would precede work context and would significantly predict both engagement and psychological health. While operationalizing PSC among the sample of 288 Australian education workers in their schools, meso- 
mediational models were tested utilizing two-level hierarchical linear modeling. Participants were comprised of teachers (80\%) and administrators (20\%), from 11 elementary schools, one high school, four colleges, one prep high school, and two other special schools. There were 288 participants for the first trial, 212 for the second a month and a half later, and 209 participants for the third trial, performed one year after the first. Respondents were recruited as part of a company stress study through briefing sessions (Dollard, 2010).

The items used were produced through a review of the literature to procure the principles which create the framework for stress prevention interventions (European Agency for Safety and Health at Work, 2002). It is possible that varying levels of PSC within the organization would be indicated by the four following documented principles of PSC:

1. Senior management must support stress prevention through commitment and active involvement.

2. All layers of a company should be involved in stress prevention.

3. Participation in health and safety issues should include employees as well as representatives from unions and health and safety administrations.

4. Companies must be attentive to health and safety contributions of workers.

Psychosocial safety climate was measured with a 4-item scale, utilizing a 5-item Likert -style response. Items were created through a review of the literature to locate principles which provoked successful stress prevention processes. It was decided that evidence of these principles would illustrate levels of PSC in companies (Hinkin, 1995). 
Engagement was measured using two items from the nine-item edition of the Utrecht Work Engagement Scale (UWES). The two items were "I am full of energy at work" and "I am enthusiastic about my job" (Hinkin, 1995).

The results of the study showed that PSC had a moderating relationship with emotional exhaustion and emotional demands and predicted a difference in employee engagement $(\beta=.64)$ due to its association with skill discretion. It also illustrated how PSC positively influenced individuals' psychological health due to its linkage with job demands (Hinkin, 1995).

\section{Job Fit}

Previous empirical studies have been conducted which show a positive relationship between job fit and employee engagement (Chen et al., 2014; Kristof-Brown, 2016; Shuck, 2011). Research by Parsa, Tesone, and Templeton (2009) showed that imperfections in the organizational selection process could be a reason for an increased intention to turnover, a by-product of employee engagement. Because of a lack of synergy with the duties and environment of the job, many decide to leave that organization in search of a suitable fit.

Empirical research conducted by Biswas and Bhatnagar (2013) showed, by means of an organizational survey, that Person-Organization fit (P-O) was influential to employee engagement levels among workers belonging to companies in northern India. In conducting their analysis of employee engagement, they evaluated both antecedent and outcome influences. Overall, they analyzed the mediating action of engagement between person-organization fit (P-O fit) and perceived organizational support (POS) as 
antecedents and organizational commitment as a consequence along with job satisfaction. Their study tested a path model through data from six Indian companies and the sample of 246 Indian management employees. It was also designed to test the validity of a relationship between employee engagement and organizational commitment. AMOS software (version 17.0) was utilized to measure the fit of the two models: (a) the onefactor model which used both constructs and (b) the two-factor version which differentiated between engagement and commitment. The study also discovered empirical support for a linkage between job satisfaction and employee engagement (Biswas \& Bhatnagar, 2013).

The researchers surveyed 300 employees who worked full-time at companies located throughout the region. The employees participated in the survey voluntarily during regularly scheduled hours at their respective job locations. The participants were promised anonymity both verbally and in writing to provoke their honest and comprehensive opinions. In addition, they were guaranteed that no individual data would be provided to the companies, only cumulative group results. The questionnaires were distributed and collected in sealed envelopes by the researchers. Out of the 300 surveys distributed, 246 participants returned their survey questionnaires to the researchers for tabulation and analysis (Biswas \& Bhatnagar, 2013).

According to the participants' responses, their average age was 33.3 years with an average of 12.3 years of work experience. Of the 221 surveys utilized, $87.1 \%$ were male and $12.9 \%$ were female. The P-O levels were measured in participants through three survey items and a four-point Likert scale $(1=$ Strongly disagree to $4=$ Agree $)$. The 
results showed a significant positive relationship $(C R=4.67$, standardized beta $=0.48)$ between P-O and engagement (Biswas \& Bhatnagar, 2013).

Further, Moreland (2013) stated that an efficient matching of employee experience and aptitude with job prerequisites and duties resulted in elevated levels of employee engagement within individuals. Conversely, when candidates were mismatched in their assigned positions, feelings of disengagement, confusion, and depression resulted which could affect other employees. She also asserted that people experienced significant stress when forced to change careers after accumulating years of education and experience in a particular field.

A suggested solution from the job fit/engagement correlation research was to first define job requirements specifically and concisely so that candidates would attain an understanding of what their duties were in advance of applying. Secondly, current employees would be administered assessments to determine which behavioral competencies were required to succeed with management, the environment, and the parameters of the job. Then, new applicants will be tested to determine the individual levels of attitude and engagement, personality and cognitive abilities, and experience and skills so that the organization can locate the individuals who best fit the established profile of success for the position (Moreland, 2013).

Once hired, assessments will be conducted with employees as an ongoing process to ensure that job fit levels are maintained and contribution to the organization's employee engagement is optimized. The process requires that companies remain agile in 
moving employees into positions where they can be most effective during their tenure (Moreland, 2013).

\section{Discretionary Effort}

Meanwhile, employee engagement has been positively associated with greater discretionary effort. The more at ease and the more an employee's personality and objectives coincide with the goals and expectations of the position, the more willing that individual will be to put forth their best effort and go beyond the basic expectations of the role. Discretionary effort has been measured through the willingness to exceed the basic requirements necessary to avoid termination by supervisory personnel, so an enhancement of discretionary effort is imperative to maximize an individual's contribution to the organization (Emde, 1996). Research has shown that employees who are categorized as engaged provide significantly increased results for their companies. Human resource practitioners can influence this essential organizational factor of success by arranging programs which will enhance discretionary effort levels within individual and work units (Psichogios, 2013).

The Canon Australia company, a wholly owned subsidiary of Canon in Japan, instituted a new program which would help to generate improved employee engagement and motivation. The company culture was underpinned by the San-ji principles of selfawareness, self-motivation, and self-management. As a result, the company developed the "i-Choose Career Enrichment Program" which utilized the tenets of San-ji and focused on those employees who felt they had reached a plateau in their careers. The program's objectives were to re-focus and engage those who wished to stay in their 
positions at Canon, employees who wished to move to another position within the company, and workers who preferred to depart entirely from the organization (Elsley, 2009).

The participants took part in three half-day training classes and a one-on-one coaching session. The content of the classes was designed around the six "Cs" of contemplating their respective career journeys, exploring convictions, considering opportunities, contributing their talents meaningfully, creating a vision of their future, and to envision conquering their career challenges.

There were a total of 89 participants in New Wales and Victoria offices with tenure ranging from less than a year to 13 years. The median amount of time spent in their current job was two to three years and the medium overall tenure with Canon was four to five years. The participants came from a wide variety of departments within the Canon organization (Elsley, 2009).

The group of employees-participants also utilized a Work Engagement Tool to explore drivers of motivation (security, belonging, expertise, self-actualization, work-life, world altruist, and community) and to identify chances to enhance their engagement and discretionary effort levels while making career decisions. The primary section of the tool measured each employee's motivational drivers, their perceptions of their current job, and motivational dissonance, or their gap between need and experience. To assist with the one-on-one interview phase and the important career decision discussed within, the tool offered an engagement risk/opportunity diagram. 
The entire program was evaluated utilizing a survey which was distributed to the 66 employees who completed the program. The quantitative component of the survey involved the re-evaluation of the Work Engagement Tool to determine pre- and postdifferences in individual engagement and discretionary effort levels as well as projected influence on productivity through the utilization of national salary data (Elsley, 2009).

Out of a total of 89 employees who participated in the Career Enrichment program, 66 people $(74 \%)$ remained in the organization and 23 people (or $26 \%$ ) chose to depart the Canon firm. Of those who chose to remain, 72\% remained in the same job, $18 \%$ transferred to similar level positions, and $18 \%$ were promoted. In rating their level of engagement upon completion of the program, those who indicated they were "more engaged" and "much more engaged" were proactively initiating discussion with management regarding career development and were willing to work on challenging projects (Elsley, 2009).

\section{Corporate Leadership Council Engagement Model}

Research completed through the work of the Corporate Leadership Council discovered that every $10 \%$ rise in levels of employee engagement fosters a $6 \%$ increase in discretionary effort (Elsley, 2009). The company's analysis tested the model by exploring whether there was a significant correlation between employee levels of engagement and resulting levels of discretionary effort and performance. The results supported CLC's model, that engagement was related to discretionary effort, as postcourse engagement did have a significant positive correlation with post-course 
discretionary effort $(r=.45, p<.01)$. The resulting inference is that increased engagement levels produce enhanced levels of discretionary effort (Elsley, 2009).

\section{Job Performance}

A significant rise in overall employee performance relative to both job-related goals and interpersonal relationships can be expected as a result of the increased presence of employee engagement and discretionary effort within workers (Wheeler, Harris, \& Sablynski, 2012). If all elements included in the proposed research model show a positive relationship, there is an end-result to the conceptual model which relates positively to a more substantial employee contribution to the company in terms of both effort and productivity.

To optimize advances in discretionary effort and job performance, each of the preceding links in the conceptual model (job fit, organizational climate, and employee engagement) must be attended to and enhanced. If any of these preceding factors are neglected, it will compromise the end results. Therefore, both human resource practitioners and scholars must create a comprehensive plan to support growth in each of the conceptual antecedents to employee engagement before realizing maximal growth in engagement and its precipitates.

A study by Williams and Seiler (1973) examined the relationship between effort

and job performance. While previous researchers had considered effort and performance to be synonymous, their study considered effort and job performance independently and evaluated the influence of effort on the quality of work performed. The Campbell and Fiske (1959) multi-trait, multi-method approach was utilized. They used the categories of 
global and dimensional to rate the variables and had participants rate themselves as well as be rated by supervisors.

The study was conducted at an engineering firm which was responsible for the service and installation of telephone hardware with 41 supervisors and 202 engineers as participants. The performance rating scales used in the study were created by Williams and Seiler (1973) specifically for engineers. The employees were rated on the five dimensions of engineering proficiency, procedural proficiency, administrative proficiency, company identification, and production,

There were two global ratings for each of effort and production. Effort was rated on a nine-point scale from "very small amount" (1) to "very large amount" (9) and performance was rated separately from "very low" to "very high" on the same scale. Job performance was defined as an individual's overall contribution to the company, while effort was defined as how hard each employee works. Each supervisor completed the two performance and two effort rating scales for their engineers in small group sessions. The supervisors rated their employees on dimensional effort, dimensional performance, measure of global effort, and measure of global performance. In addition, the engineers completed rating booklets on themselves, which were similar to those done by the supervisors. Both groups knew the other was participating and all involved were told that the evaluations were an experiment (Williams \& Seiler, 1973).

The correlation coefficients between global effort and levels of performance were .48 and .60 for self-evaluation and ratings of supervisors, respectively. While the correlations were high, they showed that effort was strongly related to performance, but 
was also independent of it. In considering the significance of these results, it is important to consider that both the supervisors and the engineers could have confused effort and its components with performance and its components because, at this time, many saw the two variables as highly indistinguishable.

\section{Summary}

Chapter II has reviewed and examined relevant employee engagement literature while providing various conceptual perspectives. Published literature pertaining to the research variables of psychological climate, job fit, discretionary effort, and job performance was also presented and discussed. These variables were then amalgamated to form two conceptual models of employee engagement. Chapter III will next describe the method by which the necessary data to test the hypotheses and the models were collected and statistically analyzed. 


\section{CHAPTER III}

\section{METHOD}

The purpose of the study and research questions are presented below. Descriptions of the research design, the population, sampling procedures, variables and instrumentation, data management, and the analysis of the data follow. A summary of related elements will then be provided at the conclusion.

\section{Purpose of the Study}

The purpose of this study was to first investigate the influence of job fit and psychological climate upon employee engagement. The second purpose was to examine the influence of employee engagement on discretionary effort and job performance.

\section{Research Questions and Hypotheses}

There are two research questions driving this study: (a) What is the influence of job fit and psychological climate on employee engagement? and (b) What is the influence of employee engagement on discretionary effort and job performance? Three hypotheses were tested to evaluate these questions:

H1: There is a positive relationship between job fit, psychological climate, and employee engagement as measured by the results of surveyed study participants.

$\mathrm{H} 2$ : There is a positive relationship between employee engagement and discretionary effort as measured by the results of surveyed study participants. 
H3: There is a positive relationship between employee engagement and job performance as measured by the results of surveyed study participants.

\section{Research Design}

The framework for the present research study was constructed with concepts and theories that are unique to the workplace. A nonexperimental design, which focuses on prevalence rates and linkages among variables, rather than causality, was utilized. Studies using research designs that are nonexperimental in nature are often correlational (except qualitative research) with the results being descriptive, and inferences being produced in response to the results being non-causal (Thompson, Bagley \& Panacek, 2007). While some have considered the nonexperimental and correlational research designs to be synonymous, correlational design is actually an analytical characteristic and not directly related to design (Cook \& Campbell, 1979).

It is important to clearly differentiate between the separate phases of analytic processes and research design because they each accomplish separate and essential purposes. This applies in the differentiation between predictive and explanatory nonexperimental research. While an explanatory research design describes the existence and effects of phenomena, the predictive nonexperimental design seeks to prognosticate the measurement of dependent variables' values through the presence of control or independent variables (Johnson, 2001). While the study does get at explanatory research when exploring the relationship among the research variables in a correlational sense, the study primarily employs a predictive, nonexperimental design. 
When conducting the data collection and analysis, then interpreting the results of a study, it is necessary to differentiate between the two research designs. Explanatory studies serve to illustrate theoretical relationships between independent and dependent variables, while predictive studies attempt to provide a means of measuring the effects of independent variables upon dependent variables for practical applications (Johnson, 2001). In the study, an explanatory nonexperimental research design was used to describe the theoretical relationship of job fit, psychological climate, employee engagement, and discretionary effort on job performance.

The theoretical influence of employee engagement (independent variable) on job performance (dependent variable) and discretionary effort (dependent variable) is further examined and highlighted as a primary goal of the research. The determination of the relationship is key to an effective application of the study's results to the hospitality workplace, the setting of this study.

\section{Population and Sample Size}

The population used for the study was cruise line customer contact center workers in the United States. The study was conducted with workers from cruise line call centers in south Florida, Eugene, Oregon, and Los Angeles, California because an overwhelming majority of domestic cruise lines are located in these cities. The cruise industry is one of the largest employers in south Florida and thus contributes significantly to the economic vitality of the region (Pabón \& Reio, 2018). In one of the few studies examining engagement in the cruise industry, Pabón and Reio found that travel agents' learning engagement, as measured by time spent playing serious computer games for training 
purposes, and knowledge acquisition positively predicted participants' cruise sales performance at the cruise line. Pabón and Reio called for more research that linked engagement of other types (e.g., job engagement, employee engagement) to important organizational outcomes. The present study answers Pabón and Reio's call by examining another type of engagement, employee engagement (defined as an emotional feeling of attachment to and absorption with one's work; Schermerlon, 2010), and its link to discretionary effort and job performance.

For conducting research that requires correlation and regression analysis such as the current study, Green (1991) provides the formula $N \geq 50+8 m$ (where $m$ is the number of independent variables) to calculate sample size requirements. For this study, where we had three independent variables $(m=3)$, we would need $50+(8)(3)=74$ cases (participants). Further, a power analysis of .80 with an effect size (i.e., $r=.30$ ) and an alpha of .05 reveals that a sample size of at least 84 would be best (Cohen, 1988). However, a larger sample size was sought to strengthen the statistical power of the study further and reduce the likelihood of a Type II error.

Taking into consideration the statistical recommendations for sample size derived from the Green (1991) formula, the research study was conducted with data procured from a sample of 307 cruise reservations agents employed at three reservation customer centers operated by two major cruise lines located in Miramar, Florida, Eugene, Oregon, and Los Angeles, California. Although it would have been ideal to randomly select a call center anywhere where they are located, the call centers in Florida, Oregon, and California were selected because they were among the largest in the U.S., thereby 
increasing the chance of acquiring the sample size needed to run the statistical analyses required to test the three research hypotheses.

\section{Variables and Instrumentation}

The following section describes the survey instruments utilized in the measurement of the variables contained within the study. The focus of the study, employee engagement, will be discussed first followed by its antecedent variables of psychological climate and job fit; in that order. From there, the outcome variables of discretionary effort and job performance will be described.

The Internet-based, survey battery presented to the participants used a 5-point Likert scale which scores each instrument according to a range from 1 (strongly disagree) to 5 (strongly agree). The total scores for each question posed to the participants were added and presented as the aggregate score with each instrument being scored separately. Although the three subscales of the Employee Engagement Scale (EES) are presented for the sake of precision, the total score was used to test the hypotheses. For example, Shuck et al. (2017) used the EES to measure employee engagement, with three subscales, but the overall total scale score was examined in the final correlational and regression analyses. The described protocol mirrors a number of empirical studies that were predictive in nature like the present study (e.g., Pabón \& Reio, 2018; Shuck, 2010). 


\section{Employee Engagement Scale}

A 12-item employee engagement scale developed by Shuck et al. (EES; 2017) was designed as a measuring tool intended for the use of HRD researchers and organizational professionals. The scale consists of the three subscales (cognitive, emotional, and behavioral) that comprise the construct of employee engagement.

Cognitive engagement can be described as the level of mental vigor directed toward the accomplishment of stated organizational objectives. Workers who display significant levels of cognitive engagement are more attentive and tend to apply a more concentrated effort while partaking of work-related tasks. Cognitive engagement is evaluated in terms of both proportion and direction considering both attentiveness and mental awareness as well as concentration and focus on work assignments (Shuck et al., 2017). A sample item for this subscale is "At work, I am focused on my job."

Emotional engagement has been described by Macey and Schneider (2008) as the volume of fervency and eagerness that employees are willing to apply to the achievement of their firm's designed goals. It is intended to measure the level of emotional attachment an employee possesses for their comprehensive work experience. Emotionally engaged employees tend to express feelings of personal meaning and a strong sense of belief in what the company seeks to achieve. They view their work assignments as a meaningful part of their being rather than something that exists externally of their psyches. A sample item from this subscale is "I feel a strong sense of belonging to my job."

Behavioral engagement relates to employees' intentions to behave in ways which yield positive outcomes for themselves and their organizations. Workers considered to 
be behaviorally engaged will display enhanced levels of discretionary effort or, an eagerness to exceed what they perceive to be the minimum required effort performance to maintain their positions. It is a pre-existing attitudinal, psychological state which provokes employees to go beyond what is expected in advance of any overt behavior and harder-working results (Shuck et al., 2017). A sample item for this subscale is "I work harder than expected to help my company be successful."

Shuck et al.'s (2017) EES scale was utilized in this study due to substantial evidence of reliability and construct validity. In that study, with the alpha levels being $.81, .73$, and .92 for CE, EE, and BE, respectively, the final scales demonstrated significant discriminant and construct validity evidence. The overall alpha was .95 . In the present research, the Cronbach's alphas were $.83, .79$, and .90 , respectively, for the subscales, and .97 overall.

\section{Antecedent Variables}

The section below describes the job fit and psychological climate variables included in the study.

Job fit. Job fit involves the process of matching work duties with the skill and experience of personnel. The perceived match between employee and duties ("job fit") was measured through the 4-item Saks and Ashforth (1997) Person-Job Fit Scale (PJS). Saks and Ashforth present reliability (Cronbach's alpha $=.94$ ) and validity (through confirmatory factor analysis) evidence. The original was a 7-point scale but was adapted for the purposes of the present research to be consistent with the other measures in the current study. Thus, the researcher utilized a 5-point Likert range with a score of 1 
(strongly disagree) indicating the lowest fit and 5 (strongly agree) representing the highest. The addition of all items included in the scale produces a cumulative job fit score. An Example of an items from the scale is "at work I have the opportunity to do what I do best every day.” In the present study, the Cronbach's alpha was .87.

Psychological climate. Psychological climate (PC) is defined as a worker's perception of the work environment in which they are engaged (Harter et al., 2002). The scale used in the present research is a brief form of Harter et al.'s (2002) scale, consisting of six items that use a 5-point Likert range with a score of 1 (strongly disagree) to 5 (strongly agree). It includes PC-related items such as "in the last seven days, I have received recognition or praise for doing good work," "my supervisor, or someone at work, seems to care about me as a person," and "at work, my opinions seem to count." The addition of all items included in the scale produces a cumulative job fit score for the survey participants. The Cronbach's alpha was .93 in the present research, while Harter et al. reported an alpha of .91 for the full scale. Through confirmatory factor analysis, Harter et al. presented strong validity evidence.

\section{Outcome Variables}

The following section details the methods utilized to measure discretionary effort and job performance with the outcome variables being examined in the current research.

Discretionary effort. In the present study, discretionary effort was measured by Frankel, Restubog, and Bednall's (2012) Discretionary Work Effort (DWE) scale. The DWE uses a 5-point Likert scale, with answers ranging from 1 (strongly disagree) to 5 (strongly agree) for each of the items. "I do more than is expected of me," "I take my job 
seriously and rarely make mistakes," and "I try hard to increase my skills to improve the quality of my work" are the three items. Each of the items related to the energy and perseverance with which respondents performed their job duties. In a series of two studies, the authors present considerable discriminant and construct validity evidence. The Cronbach's alpha for the scale in Frankel et al.'s studies was .85 and .87, respectively, while it was .88 in the current study.

Job performance. When conducting survey research, researchers often advise limiting the number of items as much as feasible to reduce the likelihood of respondent fatigue and increase the likelihood that prospective respondents will choose to complete the survey. Brief measures of job satisfaction, job engagement, general self-efficacy, and job performance, for instance, have been used successfully with evidence of reliability and validity in organizational research (e.g., Doblier, Webster, McCalister, Mallon, \& Steinhart, 2005; Harter et al., 2002; Wanous \& Reichers, 1996). With this knowledge, I employed a two-item scale of job performance designed specifically for the study consistent with Reio \& Wiswell (2000). The two job performance questions were as follows:

JP1. My average monthly booking production exceeds goals set by management.

JP2. I consistently produce more monthly bookings than my colleagues.

These items directly address production as measured by the organizations participating in this research and provide a clearly understandable means of illustrating customer contact 
center productivity. Each of the items was scored on a 5-point Likert scale from 1

(strongly disagree) (1) to 5 (strongly agree). These items were designed to evaluate task performance across different channels and departments of production within the two companies studied. The Cronbach's alpha for this scale in the present research was .81.

\section{Procedures}

The study utilized an Internet-based self-report survey for data collection. These types of surveys are increasingly popular, as compared to other survey methods, such as telephone and mail surveys (Rada, Diaz, \& Dominguez-Alvarez, 2014). Internet selfreport questionnaires have been shown to be more expedient and cost efficient, while providing researchers the ability to reach participants around the world and receive responses within in a matter of minutes (Heiervang \& Goodman, 2011). The section below details the survey used in the study along with the methods employed in determining the sample that would be surveyed.

\section{Internet-Based Self-Report Survey}

The Internet-based self-report survey enabled the procurement of the relevant research data related to testing the hypotheses guiding the study. The web link for the survey was sent to a Human Resources professional for each of the two selected cruise lines, who then forwarded the web link to the prospective sample of participants. Thus, the prospective participants and participants remained anonymous to the researcher. 
Advantages and disadvantages of using Internet-based e-mail surveys. While

web-based surveys have been shown to be more convenient and less expensive than telephone and mail surveys, there are significant drawbacks to the e-mail questionnaire procedure. For example, face-to-face interviewers are able to provoke comprehensive answers and motivate respondents to complete the entire survey. Additionally, a webbased survey may oversample from socially advantaged groups with greater technological knowledge and advanced literacy because only those with access to computers and familiarity with the e-mail process can participate (Heiervang \& Goodman, 2011). The selective participation can potentially affect the validity of a research study. Therefore, it is essential that researchers consider this possibility of bias and take the necessary steps to avoid or minimize it within their contextual data collection framework. The problem was avoided in this research because everyone had a computer on their respective desks and had access to the Internet.

\section{Measurement, Sampling, and Nonresponse Error}

Measurement error is an important factor to consider when collecting data for a research study. It can be defined in the context of the current study as inaccuracies in the wording of questionnaire items, survey presentation, and answering behavior of the participants. Meanwhile, sampling error involves surveying a sample within the overall population which is not a true representation of the characteristics of the population, while nonresponse error involves the skewing of survey results as a result of complete survey participation and completion on the part of the respondents (Dillman, Smyth \& Christian, 2009). The possibility of nonresponse error was lessened by following the data 
collection protocol of Dillman et al. (2009) where prospective participants were prenotified about the survey, as well as queried three times. Dillman et al. (2009) claimed that following these pre-planned steps tended to maximize the integrity of the data collection and sampling process.

Possible measurement error was minimized by conducting an initial pilot survey, containing proposed survey items, prior to the actual data collection, which served as a means of examining the accuracy and clarity of questionnaire directions, items, and responses. Based upon the results of the initial pilot survey, potential errors were evaluated before revisions to the questions and format were made (Dillman, 2007).

To minimize possible sampling error, each participant was provided an equal opportunity to participate in the survey along with providing pre-notifications and followup communications before and after the survey mailing (Dillman et al., 2009). These actions served to enhance the response rate of the survey and offered the researcher greater volume and depth of data by providing each individual within a selected population a similar opportunity for participation in the survey (Shuck, 2011).

\section{Survey Procedure}

Prior to conducting research, the Florida International University office of University Graduate Studies (UGS) accepted the dissertation subject and permission from the Florida International University Institutional Review Board (IRB) was obtained to perform the study using human subjects. The evaluation and approval of the planned research from the IRB was a necessity before the study could begin. 
The Tailored Design Method described by Dillman et al. (2009) was utilized as a guide to formulating and executing the survey research necessary for the study. Dillman's method is an established and trusted method of procedure for researchers.

According to the four-stage framework outlined by Dillman et al. (2009), the intent of the study was explained to all individuals associated with the research prior to proceeding. It was imperative, both ethically and practically, that all involved with the survey understood the reasons and potential implications behind it.

Once completed, in Stage One, four individuals with knowledge of and experience in human resource and engagement practice and study were employed to review the survey (content validity). Included in the survey review group were a university professor in the adult education/human resource development discipline, a major cruise line human resource director, an adult education/human resource development doctoral candidate, and a professional consultant in the area of organizational behavior. With their identities and respective contributions kept confidential, feedback was requested and considered in the editing of the content to ensure its quality and reliability in collecting the optimally relevant data.

In Stage Two, the proposed survey was evaluated by an experienced survey research practitioner to ascertain its overall suitability and adherence to effective survey practices. The survey content was again edited by mutual accord of the survey expert and the researcher.

Stage Three of the survey review administered the survey to a select group of respondents $(N=30)$ from the travel industry (a group similar to the sample population of 
cruise line reservation agents utilized in the study). The participants were asked to complete the survey and their feedback was sought pertaining to the overall quality of instructions and relevance of survey items being recorded and evaluated. Information gathered was incorporated into refining the final instructions and survey items. The final step of the review process, Stage Four, involved the participation of three graduate students from the Florida International University Chaplin School of Hospitality and Tourism Management taking the survey and providing feedback for consideration. The information gained was used to refine the final instructions and survey items even further.

Upon completion of the four stages, one Human Resource Director at each cruise line was contacted and asked to participate in this research by serving as the individual who would distribute the web links for the survey battery to prospective participants at the companies. The action served to ensure that the survey is promptly and properly distributed in accordance with company policies and procedures.

The interval-scheduling framework constructed by Dillman et al. (2009) was employed to introduce and provide an overview of the research, direct participants to the survey link, then send completion reminders to the survey participants. The framework, borrowed from the Tailored Design Method of Dillman et al. (2009), was scheduled as follows: 
Table 1

Interval-Scheduling Framework for Survey Battery Distribution

1. Survey invitation e-mail sent (one week prior to survey date).

2. Survey pre-notification e-mail sent (three days after initial invitation sent).

3. Survey web link in the form of an URL will be distributed.

4. First survey reminder e-mail (one week post-survey availability).

5. Second survey reminder e-mail (two week post-survey availability).

Thank you e-mail and survey closure (four days after second survey reminder).

In Step One, the survey participants were forwarded an introductory invitation email requesting and encouraging their participation in the study. The prospective respondents were then e-mailed pre-notification three days later, which included a welcome message, survey instructions, and a comprehensive notice of confidentiality. In preparation for the survey data distribution and collection and in continued accordance with the prescribed methods of Dillman et al.'s (2009) framework, the survey battery was uploaded into the SurveyMonkey (http://www.surveymonkey.com) online computer survey program. Four days after the pre-notification was sent, participants were sent the web-based survey battery with explicit directions that they: (a) possessed the ability to complete the survey at their own discretion, (b) could opt-out at any time they felt inclined to do so, and (c) were assured that their confidentiality was protected through the use of unique URLs assigned to each survey. The use of these unique URLs was to ensure also that the participants could not be identified by name while protecting against response duplication. One week later, a reminder with the survey URL link included was 
sent; after an additional week, the second and final reminder with the survey URL was sent. Last, four days later, participants were sent a thank you message.

The survey results were downloaded from the SurveyMonkey program onto a digital electronic file, which was exclusively available to the researcher. To maintain complete confidentiality, none of the responses or access to the survey mechanism were made available to anyone other than the researcher. The study data were downloaded to a portable flash-drive, which was stored in a personal safe deposit box within the vault of a local bank. The file loaded onto the portable drive contains only coded data and URLs without names of the individual study participants.

\section{Data Analysis}

The data collected for this research study were analyzed through the utilization of the SPSS 22.0 statistical analysis program. A combination of correlational and predictive techniques was employed to analyze the data. The correlational analyses were used to determine the strength and direction of relationships between the antecedent variables of job fit and psychological climate and employee engagement as well as the outcome variables of discretionary effort and job performance. The regression analyses were used to determine the unique variance being explained in discretionary effort and job performance by each of the antecedent variables.

H1: There is a positive relationship between job fit, psychological climate, and employee engagement as measured by the results of surveyed study participants. 
First, a correlational analysis was conducted to determine the strength and direction of relationships among job fit, psychological climate, and employee engagement. Second, a hierarchical regression analysis was conducted to determine the unique variance that job fit and psychological climate explained in employee engagement.

$\mathrm{H} 2$ : There is a positive relationship between employee engagement and discretionary effort as measured by the results of surveyed study participants.

A correlational analysis was first performed to determine the strength and direction of relationship between employee engagement and discretionary effort. Next, a hierarchical regression analysis was performed to determine the amount of variance that employee engagement explained in discretionary effort.

H3: There is a positive relationship between employee engagement and job performance as measured by the results of surveyed study participants.

A correlational analysis was first conducted to determine the strength and direction of relationship between employee engagement and job performance. Second, a hierarchical regression analysis was conducted to determine the amount of variance that employee engagement explained in job performance.

\section{Summary}

Chapter 3 has presented the procedures for participant selection and data collection. This process included survey participant determination and sample size, the research design that guided the data collection, analytical procedures for hypothesis 
testing, and a detailed description of the research instruments. Additionally, the advantages and disadvantages of Internet-based surveys were delineated. 


\section{CHAPTER IV}

\section{RESULTS}

The following chapter provides the results of the research divided into four main sections: the demographics and background of the survey sample, a correlational analysis of the outcome variables, an evaluation of the research hypotheses, and a summarization of the section. Both correlational and hierarchical regression analyses were utilized to evaluate the hypotheses and to assess the respective correlations between the selected variables and the two models of employee engagement as well. Hierarchical regression was particularly helpful in illustrating how individual or groups of variables can influence certain outcomes (Gelman, 2007).

\section{Background of the Sample}

Three hundred and seven $(N=307)$ respondents participated in this study. The respondents' backgrounds, in terms of age, ethnicity, gender, level of education, and job experience, are evaluated below (see Table 2).

\section{Age}

A frequency analysis of age indicated that $51.8 \%(n=159)$ of the respondents reported belonging to the $18-25$ age group, $28.7 \%(n=88)$ to the $26-36$ group, $10.7 \%(n$ $=33)$ to the $37-47$ group, $2.9 \%(n=9)$ to the $48-59$ group, $0.3 \%(n=1)$ to the 60 and over group, while $5.5 \%(n=17)$ chose not to answer. 


\section{Ethnicity}

An analysis of respondents' ethnicity showed that $33.9 \%(n=104)$ identified as White, $24.8 \%(n=76)$ identified as Hispanic, $22.1 \%(n=68)$ were Black, $7.5 \%(n=23)$ reported as Asian, 6.2\% $(n=19)$ identified themselves as Other, and 5.2\% $(n=16)$ chose not to respond to the question.

\section{Gender}

An analysis of respondents' gender was conducted to determine the proportion of each participating in the study. Approximately $56 \%(n=172)$ of the sample was female and $38 \%(n=117)$ of the sample was male, while $6 \%(n$

$=18)$ of the sample did not report their gender.

\section{Job Experience}

A frequency analysis of job experience indicated $42.3 \%(n=130)$ of participants had less than 1 year on the job, 24.8\% $(n=76)$ had been employed in their positions for between 1 and 2 years, $21.2 \%(n=65)$ reported having between 2 and 5 years of experience in their current job, $4.9 \%(n=15)$ reported 5 to 10 years in their position, and $.9 \%(n=3)$ possessed more than 10 years of experience in their job as reservation agents for their current company, and 5.9\% $(n=18)$ opted not to respond to the question.

\section{Level of Education}

The level of respondents' education was measured and analyzed. Approximately $54 \%(n=166)$ of participants reported High School as their highest level of education. Another $14.7 \%(n=45)$ possessed a two-year degree while $23.4 \%(n=72)$ were four- 
year college graduates. Post-graduates represented .6\% $(n=2)$ of those surveyed and the remaining $7.2 \%(n=22)$ of participants chose not to respond to the question.

All participants were employed in similar positions as reservations agents or telesales consultants employed in customer contact centers within the cruise industry. This relatively homogenous sample in terms of job responsibility was utilized to compile and apply results pertaining specifically to these reservations and sales agents, and not to involve supervisory or management employees at any level. 


\begin{tabular}{|c|c|c|c|}
\hline $\begin{array}{l}\text { Table } 2 \\
\text { Demographic Frequency }\end{array}$ & & & \\
\hline Category & Variable & $f$ & $\%$ \\
\hline Age & $\begin{array}{l}18-25 \\
26-36 \\
37-47 \\
48-60 \\
60+ \\
\text { No Response }\end{array}$ & $\begin{array}{c}159 \\
88 \\
33 \\
9 \\
1 \\
17\end{array}$ & $\begin{array}{l}51.8 \\
28.7 \\
10.7 \\
2.9 \\
0.3 \\
5.5\end{array}$ \\
\hline Gender & $\begin{array}{l}\text { Male } \\
\text { Female } \\
\text { No Response }\end{array}$ & $\begin{array}{c}172 \\
117 \\
16\end{array}$ & $\begin{array}{c}56.0 \\
38.1 \\
5.2\end{array}$ \\
\hline Education & $\begin{array}{l}\text { High School } \\
\text { 2-yr College } \\
\text { 4-yr College } \\
\text { Master's } \\
\text { Doctorate } \\
\text { No response }\end{array}$ & $\begin{array}{c}166 \\
45 \\
72 \\
2 \\
0 \\
22\end{array}$ & $\begin{array}{c}54.1 \\
14.7 \\
23.4 \\
0.6 \\
0.0 \\
7.2\end{array}$ \\
\hline Ethnicity & $\begin{array}{l}\text { White } \\
\text { Hispanic } \\
\text { Black } \\
\text { Asian } \\
\text { Other } \\
\text { No Response }\end{array}$ & $\begin{array}{c}104 \\
76 \\
68 \\
23 \\
19 \\
16\end{array}$ & $\begin{array}{c}33.9 \\
24.8 \\
22.1 \\
7.5 \\
6.2 \\
5.2\end{array}$ \\
\hline Experience & $\begin{array}{l}<1 \mathrm{yr} . \\
1-2 \mathrm{yr} . \\
2-5 \mathrm{yr} . \\
5-10 \mathrm{yr} . \\
10+\text { yr. } \\
\text { No response }\end{array}$ & $\begin{array}{c}130 \\
76 \\
65 \\
15 \\
3 \\
18\end{array}$ & $\begin{array}{c}42.3 \\
24.8 \\
21.2 \\
4.9 \\
0.9 \\
5.9\end{array}$ \\
\hline
\end{tabular}




\section{Examination of Hypotheses}

The hypotheses in this study, which proposed that job fit and psychological climate were related to employee engagement and that engagement was related to discretionary effort and job performance, were tested first using correlational analyses. Subsequently, hierarchical regression analysis was performed to test the two engagement models (Figure 1a—Discretionary Effort as outcome; Figure 1b-Job performance as outcome). Hierarchical regression analysis, governed by theory and research, is an advanced form of linear regression that allows the researcher to statistically control, stepby-step, variables predicted to be linked to the dependent variable. This regression approach is in contrast to stepwise regression where each step of the analysis is governed by statistical analysis and is thus theoretical, which is not preferable for hypothesis testing. Stepwise regression is more appropriate for the preliminary stages of exploratory work (Tabachnick \& Fidell, 2001).

First, three theoretically and empirically relevant demographic control variables (gender, ethnicity, job experience; Elsey, 2009; Kahn, 1990; Shuck et al., 2017) were entered as the first step of a hierarchical regression analysis. These variables are relevant because they have been linked, albeit weakly, by previous researchers like Shuck et al. to employee engagement. Although they are not of primary interest in the present research, the researcher determined that it would be best to control for these demographic variables to get a clearer sense of the degree job fit and psychological climate are linked to engagement, and engagement to the two dependent variables, absent of the possible confounding effects of the demographic variables. The second step entailed entering the 
hypothesized job fit and psychological climate research variables. The third and final step involved utilizing the employee engagement variable.

Certain key assumptions about correlational and hierarchical regression analyses techniques were reviewed, including linearity (reviewed bivariate scatterplots of variables and they provided evidence of relatively linear lines; Tabachnick \& Fidell, 2001) and multicollinearity (intercorrelations among variables were less than .90, therefore there was little evidence of multicollinearity; Green, 1991). In addition, tolerance (.10 minimum recommended) and variance inflation factors (VIF; maximum of 10.0) were examined; all tolerances $\left(1-R^{2}\right)$ and VIFs $1 /\left(1-R^{2}\right)$ and VIFs were within recommended range (Tabachnick \& Fidell, 2001), again suggesting that multicollinearity was not a significant issue with this research. Homoscedasticity was also reviewed (variability in scores for one variable is roughly the same at all values of the other variable- related to normality). Bivariate scatterplots were reviewed first for evidence of a cone-shaped versus a funnel shape. The presence of a cone shape suggested the variance of residual error was constant for all values of the antecedent variables, which was desirable (Tabachnick \& Fidell, 2001). Therefore, because the assumptions for linearity, lack of multicollinearity, and homoscedasticity were met, the results of the correlational and regression analyses could be interpreted without undue concern for possible bias.

\section{Analysis of Variable Scales}

Table 3 below displays the descriptive statistics associated with each scale utilized in the study with the respective means and standard deviations of the scales used to measure each of the research variables included. The mean of each scale represents the 
average cumulative score of survey items employed to measure the associated study variables while the standard deviation is a product of the variance observed between individual survey responses. Also relative to the scales used to quantitatively represent the study variables, Table 4 below illustrates their intercorrelations.

\begin{tabular}{|l|c|c|c|}
\hline Table 3 & & & \\
Descriptive Statistics & & $S D$ & $N$ \\
\hline Scale & $M$ & 5.96 & 307 \\
\hline ORGFIT & 26.63 & 6.07 & 307 \\
PSYCLIMATE & 23.87 & 9.82 & 307 \\
ENGAGETOTAL & 40.60 & 5.21 & 307 \\
DETOTAL & 20.05 & 2.21 & 307 \\
JPTOTAL & 7.49 & \\
\hline
\end{tabular}

Note. $N=307$. ORGFIT $=$ person-job fit; PSYCLIMATE = psychological climate; ENGAGETOTAL = employee engagement total; DETOTAL = discretionary effort total; JPTOTAL $=$ job performance total.

\begin{tabular}{|c|c|c|c|c|c|}
\hline $\begin{array}{l}\text { Table } 4 \\
\text { Correlations }\end{array}$ & & & & & \\
\hline & JOB FIT & PSYCLIM & DETOTAL & ENGAGE & JP \\
\hline $\begin{array}{cc}\text { JOB FIT } & \begin{array}{c}\text { Correlation } \\
\text { Significance }\end{array}\end{array}$ & 1.00 & & & & \\
\hline $\begin{array}{l}\text { PSYCLIM Correlation } \\
\text { Significance }\end{array}$ & $\begin{array}{l}.66 \\
.000\end{array}$ & 1.00 & & & \\
\hline $\begin{array}{r}\text { DETOTAL Correlation } \\
\text { Significance }\end{array}$ & $\begin{array}{l}.80 \\
.000\end{array}$ & $\begin{array}{l}.63 \\
.000\end{array}$ & 1.00 & & \\
\hline $\begin{array}{r}\text { ENGAGE Correlation } \\
\text { Significance }\end{array}$ & $\begin{array}{l}.81 \\
.000\end{array}$ & $\begin{array}{l}.60 \\
.000\end{array}$ & $\begin{array}{l}.74 \\
.000\end{array}$ & 1.00 & \\
\hline $\begin{array}{l}\text { Correlation } \\
\text { Significance }\end{array}$ & $\begin{array}{l}.80 \\
.000\end{array}$ & $\begin{array}{l}.62 \\
.000\end{array}$ & $\begin{array}{l}.77 \\
.000\end{array}$ & $\begin{array}{l}.71 \\
.000\end{array}$ & 1.00 \\
\hline
\end{tabular}

Note. $N=307$. PSYCLIM = Psychological Climate, DETOTAL = Discretionary Effort, ENGAGE = Employee Engagement; JP = Job Performance 


\section{Demographic Control Variable Correlations}

The correlations among gender, ethnicity and job experience with psychological climate, job fit, employee engagement, discretionary effort and job performance were examined. In all cases, the relationships were statistically nonsignificant $(r \mathrm{~s}<.12, p \mathrm{~s}>$ .05). Still, the decision was made to include the control variables in the regression analyses because it is possible when entered as a set or block in the hierarchical regression analyses, the variables could explain significant, unique variance in the dependent variable (Tabachnick \& Fidell, 2001).

\section{Hypothesis 1}

H1 stated that there would be a positive relation among job fit, psychological climate, and employee engagement. Zero-order correlational coefficients between the variables within the study were evaluated for relative significance in accordance with effect size standards and ranges developed by Cohen (1988) illustrated that correlational coefficients less than .28 are small effects, those between .28 and .49 are considered medium, and effects greater than .49 are large (Shuck, 2011).

The correlational analyses revealed that job fit related positively with both psychological climate $(r=.66, p<.001)$ and employee engagement $(r=.81, p<.001)$. Likewise, psychological climate positively related with employee engagement $(r=.60, p$ $<.001)$. Therefore, the first hypothesis was supported. Each of the correlations demonstrated large effect sizes. 
To further examine the links among the variables after statistically controlling for possible confounding variables (gender, ethnicity, job experience), hierarchical regression analysis was used (see Table 5 below). The first step of the regression analysis entailed entering the possible confounding demographic variables as a block $\left(R^{2}=.047, p\right.$ $=.001)$. Second, the job fit and psychological climate variables were entered as a second block to determine how much incremental variance they explained in the dependent variable $\left(\Delta R^{2}=.782, p<.001\right)$. Demonstrating a large effect size, the overall variance (Total Adjusted $R^{2}$ ) explained was $.829(p<.001)$. Interestingly, the only demographic variable that contributed significantly to the regression equation $(\beta=-.10, p<.001)$ was job experience. Thus, with a standard deviation increase in job experience, employee engagement would decrease $.10 S D$. Similarly, with a standard deviation increase in job fit and psychological climate, after controlling for the background variables, employee engagement would increase $.79 S D$ and $.15 S D$, respectively. The significance of all this is that even after controlling for possible confounding variables, job fit and psychological climate had a positive effect on employee engagement, thus supporting the first hypothesis. 
Table 5

Summary Hierarchical Regression Analysis with Job Fit and Psychological Climate Predicting Employee Engagement after Controlling for Demographic Variables

\begin{tabular}{lllll}
\hline Variable & $\beta$ & $R$ & $R^{2}$ & Sig. $F$ \\
\hline Step 1 & & & & \\
Ethnicity & .013 & & & \\
Gender & .042 & & .047 & \\
Job Experience & $-.100 * * *$ & & & \\
Block & & .24 & & \\
Step 2 & & & .001 \\
Job Fit & & & .782 & .000 \\
Psychological Climate & $.15^{* * *}$ & & .81 & \\
Block & & & & \\
Total Adjusted $R^{2}$ & & & & \\
\hline
\end{tabular}

Note. $N=307 ; * * * p<.001$

\section{Hypothesis 2}

In $\mathrm{H} 2$, it was forecasted that there would be a positive association between employee engagement and discretionary effort. The significance of the correlational coefficients was evaluated utilizing zero-order correlational coefficients according to established effect size standards (Cohen, 1998). As shown in Table 4 above, employee engagement was discovered to positively linked to discretionary effort ( $r=.74, p<.001$ ). 
Therefore, the second hypothesis was supported. The results suggest that individuals reporting higher levels of employee engagement were tending to display higher levels of discretionary effort.

To further examine the link between employee engagement and discretionary effort, hierarchical regression analysis was employed (see Table 6 below). This analysis corresponds with testing Figure 1a presented in Chapter 1. In the first block, gender, ethnicity, and job experience were entered $\left(R^{2}=.05, p=.003\right)$. Second, job fit and psychological climate were entered $\left(R^{2}=.67, p<.001\right)$. In the third and final block, employee engagement was entered $\left(R^{2}=.04, p<.001\right)$. Overall, the adjusted $R^{2}$ was .761 ( $76.1 \%$ of variance explained), demonstrating a large effect size. The only significant background variable in the first block predicting the dependent variable was job experience $(\beta=0.19, p<.001)$. Job fit $(\beta=.42, p<.001)$, but not psychological climate, $(\beta=-.04, p>.05)$, had a positive effect on discretionary effort in the second block. Employee engagement's effect on discretionary effort was also significant $(\beta=0.50, p<$ $.001)$. What the results suggest is that after statistically controlling for the demographic background variables, and job fit and psychological climate, employee engagement demonstrated a powerful effect on discretionary effort, further supporting the second hypothesis. Importantly, a standard deviation increase in employee engagement would be linked to a $.50 S D$ increase in discretionary effort, holding all the other variables constant. 
Table 6

Summary Hierarchical Regression Analysis with Job Fit, Psychological Climate, and Employee Engagement Predicting Discretionary Effort after Controlling for Background Variables

$\begin{array}{llllll}\text { Variable } & \beta & R & R^{2} & \text { Sig. } F\end{array}$

Step 1

Ethnicity .113

Gender

Job Experience

Block

Step 2

Job Fit $.81 * * *$

Psychological Climate

.04
.024

$-.189 * *$

.047

.003

Block

.85

.674

.000

Step 3

Employee Engagement $.50 * * *$

Block

.88

.040

.000

Total Adjusted $R^{2}$

.761

.000

Note. $N=307 ; * * * p<.001$ 


\section{Hypothesis 3}

To test the third hypothesis where employee engagement was predicted to be positively related to job performance, a correlational analysis was performed.

Demonstrating a large effect size, the result was $r=.71, p<.001$, thereby supporting the third hypothesis.

The next step was to examine the link between employee engagement and job performance via hierarchical regression analysis (see Table 7 below). This analysis corresponds to Figure $1 \mathrm{~b}$ in Chapter 1. Gender, ethnicity, and job experience were entered in the first block $\left(R^{2}=.02, p=.058\right)$. Next, job fit and psychological climate were entered $\left(R^{2}=.66, p<.001\right)$. In the third and final block, employee engagement was entered $\left(R^{2}=.02, p<.001\right)$. Overall, the adjusted $R^{2}$ was $.694(69.4 \%$ of variance explained), demonstrating a large effect size. None of the background variables in the first block had a significant effect on the dependent variable $(\beta \mathrm{s}<-0.01, p \mathrm{~s}>.05)$. Job fit $(\beta=.71, p<.001)$ and psychological climate $(\beta=.16, p<.001)$ both had significant, positive effects on job performance in the second block. Employee engagement's positive effect on job performance was also significant $(\beta=0.34, p<.001)$. The results indicate that after statistically controlling for the demographic background variables, and job fit and psychological climate, employee engagement had a powerful positive effect on job performance, further supporting the third hypothesis. Significantly, a standard deviation increase in employee engagement would be linked to a $.34 S D$ increase in job performance, holding all other variables constant. 
Table 7

Summary Hierarchical Regression Analysis with Job Fit, Psychological Climate, and Employee Engagement Predicting Job Performance after Controlling for Demographic Variables

$\begin{array}{llllll}\text { Variable } & \beta & R & R^{2} & \text { Sig. } F\end{array}$

Step 1

Ethnicity

.027

Gender

Job Experience

Block

Step 2

Job Fit

Psychological Climate $.71 * * *$

Block

Step 3

Employee Engagement $.34 * * *$

Block

Total Adjusted $R^{2}$

Note. $N=307 ; * * * p<.001$
.16

.015

.058 $\begin{array}{lll}.83 & .659 & .000\end{array}$

\section{Summary}

Results of the correlational and hierarchical regression analyses supported the hypotheses proposed in this study. The correlational analyses revealed positive 
associations among job fit, psychological climate, employee engagement and the two dependent variables, discretionary effort and job performance. Even after controlling for the demographic variables, job fit and employee engagement uniquely predicted discretionary effort. As for job performance, after controlling for the background variables, job fit, psychological climate and employee engagement significantly and uniquely predicted job performance. For both regressions, employee engagement had a powerful positive effect on discretionary effort and job performance. Chapter 5 will proceed to evaluate the results and implications of these findings for scholars and practitioners. 


\section{CHAPTER V}

\section{DISCUSSION}

Chapter 5 summarizes the research study and offers a discussion of its results. Implications for theory, research and practice along with the limitations and recommendations for future research are also presented.

\section{Summary of the Study}

This research answers Pabón and Reio's (2018) call for more employee engagement research and its possible link to important organizational outcomes (i.e., discretionary effort and job performance) in the hospitality industry. Answering this call was important because it tested engagement theory in a relatively understudied setting, thereby helping to extend it. Based on Kahn's (1990) engagement theory and extensive empirical research (e.g., Harter et al., 2002; Reio \& Sanders-Reio, 2011; Saks, 2006; Shuck et al., 2017), two engagement models were developed and tested. Job fit and psychological climate and engagement were used to predict unique variance in discretionary effort in the first model and job performance in the second. Support was found for each model in that employee engagement was a strong predictor of each.

While the concept of engagement has captured the imagination of HRD researchers and practitioners and management professionals over the past two decades, it remains one in need of more empirical research and understanding to flesh out its links and contributions to meaningful individual and organizational outcomes. There persists a significant level of controversy about its meaning and theoretical underpinnings (Shuck 
et al., 2017). In addition, a widening fissure has developed between researchers who view engagement as a psychological state of mind and organizational professionals who approach engagement as a workforce strategy (Truss et al., 2014).

Hui et al. (2007) discovered that $80 \%$ of engaged employees were relatively productive and less likely to leave their company in the short-term than those who are classified as disengaged. Further, Howard and Foster (2009) concluded that employee engagement enhances not only the productivity of a firm, but also its public image given the reduction of turnover among engaged employees. Indeed, Stone et al. (2009) found that $70 \%$ of job candidates perceived a company with a lower turnover rate as being more desirable to work as they seemed to be more employee-focused and financially successful.

In support of the theory that engagement enhances performance, a study by Macey et al. (2009) described that within a sample of 65 organizations in a variety of industries, the top $25 \%$ rated companies on a selected engagement index realized a larger profitability and more than twice the amount of shareholder value in comparison to the lowest $25 \%$ of the research sample. Internally, engaged employees also tend to maintain more constructive and tranquil working relationships with their management superiors (Van den Broeck, DeWitte, \& Lens, 2008), while remaining more receptive to ideas of organizational unity and team spirit (Hallberg, 2007).

Shuck et al. (2017) found that employee engagement with respect to workers' positions and job-related duties may yield a significant influence upon both employee satisfaction and the ability to maintain an appropriate and productive level of motivation 
with respect to the performance of their work. It is generally accepted that the more engaged a worker is with his or her job, the more likely they can continue to perform and stay in congruence with the labor paradigms and supervision prescribed by the organization's management (Shuck et al., 2017). Therefore, the implementation of new management paradigms to enhance engagement is arguably necessary for organizations to gain a competitive advantage (i.e., through its contributions to greater efficiency, quality, innovativeness and customer responsiveness - the four building blocks of competitive advantage) [Ferguson \& Reio, 2010]) (Salanova, 2007).

The variables of job fit (the degree to which an individual's personality and values fit with their assigned job), psychological climate (employees' interpretation of their work environment in relation to their perception of wellbeing), employee engagement, discretionary effort (the willingness to surpass the minimal results expected to avoid termination), and job performance are factors which can contribute to the overall competitive capability of a firm (Shuck et al., 2011). Stores of intangible human assets are embedded within firms' personnel, with the challenge of HR and management personnel to design compensation systems that support optimal employee behavior (Offstein, Gnyawali, \& Cobb, 2005).

The employee engagement models (see Figures 1a and 1b) in this research tested the notion that employees in positions that match well with their interests and values (job fit; Resnick, 2009) and contain supportive psychological climates (Brown \& Leigh, 1996; Johns, 2001) will exhibit greater levels of engagement. In turn, the increased levels of 
engagement would contribute unique variance to both discretionary effort (Figure 1a) and job performance (Figure 1b).

The purpose of this study was two-fold: first, to investigate the influence of job fit and psychological climate upon employee engagement. The second purpose was to examine the influence of employee engagement on discretionary effort and job performance.

There were three hypotheses tested to evaluate these questions:

H1: There is a positive relationship between job fit, psychological climate, and employee engagement as measured by the results of surveyed study participants.

$\mathrm{H} 2$ : There is a positive relationship between employee engagement and discretionary effort as measured by the results of surveyed study participants.

H3: There is a positive relationship between employee engagement and job performance as measured by the results of surveyed study participants.

A survey battery was used to evaluate the relationships among the study variables, while previously published theoretical, conceptual, and empirical literature was utilized to undergird the research. Correlational and hierarchical regression analytical methods were used to assess the models and the associated hypotheses. The results of the correlational analyses illustrated that psychological climate and job fit were positively and significantly correlated with employee engagement and, in turn, engagement was significantly correlated with both discretionary effort and job performance. Further, the hierarchical regression analyses revealed that after controlling for gender, ethnicity, and 
job experience, job fit and psychological climate, employee engagement contributed unique incremental variance to predicting discretionary effort and job performance.

\section{Discussion of the Results}

The following section discusses the results of each hypothesis tested in the study. The research results illustrated statistically significant relationships between the research variables. The first hypothesis examined was $\mathrm{H} 1$, followed by $\mathrm{H} 2$, then $\mathrm{H} 3$, before the section concludes with a summary.

\section{Hypothesis 1}

The first hypothesis in the study tested the idea that there was a significant relationship between job fit, psychological climate, and employee engagement. Results from the correlational analysis indicated there was a significantly positive relationship between each of the three variables. The hierarchical regression analyses also revealed that after controlling for gender, ethnicity, and job experience, job fit and psychological climate had positive effects on employee engagement. With the results of the research demonstrating support for $\mathrm{H} 1$, the null hypothesis was therefore rejected.

The following discusses the results pertaining to the antecedent variables and their respective associations with employee engagement. It begins first with job fit, then psychological climate.

Job fit. In the present research, increased job fit was linked to greater employee engagement. The effect size was moderate, yet significant. A standard deviation increase in job fit would lead to a $.15 S D$ increase in employee engagement. This finding supports 
previously published research on job fit and its positive relationship with engagement by not only Biswas \& Bhatnagar (2013), but also Moreland (2013). In both studies, job fit was found to be an essential prerequisite to not only employee engagement, but also employee social and psychological well-being. Therefore, reduced levels of well-being as a result of poor job fit may equate to a decreased presence of employee engagement in the organizational workforce (Saks, 2006).

Further, Moreland (2013) discovered when candidates were mismatched in their assigned positions, feelings of disengagement, confusion, and depression result, which could carry over to other employees. Moreland also asserted that people experienced significant stress when forced to change careers after accumulating years of education and experience in a particular field. This lent support to the findings of Kahn (1990) who stated that employees find their positions within organizations to be less safe and meaningful when they are intellectually, psychologically, and socially mismatched with their jobs. Given the results of these previous studies and the present research, it seems relevant that companies should match employees' attributes and objectives with their positions to allow them to feel more at ease and in congruence with the mission of the company (i.e., job fit), to promote increased levels of employee engagement (Chen et al., 2014; Kristof-Brown, 2016).

In addition, Laschinger and Finegan (2005) found that employees also exhibited higher levels of empowerment (particularly autonomy) when a significant fit existed between their expectations and the actual situation of their work, resulting in increased levels of engagement. Their research supported the theory that empowerment wielded an 
influence on the six areas of workloads thought to be precursors of employee engagement. The study demonstrated how an empowering workplace produced increased levels of control in relation to their job duties, better workload manageability, enhanced frequency of recognition and rewards, more equitable organizational procedures, augmented effectiveness of relationships between coworkers, and increased congruence between company and employee values. The result was more significant levels of employee engagement.

As supported by the results of this study, job fit may need to be addressed if the goal of increased employee engagement is to be attained within an organization. Without adequate levels of job/employee fit, employee engagement becomes less likely.

Psychological climate. In the current research, psychological climate was positively and powerfully linked to employee engagement. Dollard (2010) described how psychological climate was a significant driver of employee engagement. Dollard created a model of psychosocial safety climate (PSC) to define the roots of job demands, psychological health, and employee engagement. PSC combines psychological safety and the safety climate, both of which serve to affect employees' psychological health. Workers who experience a team environment that is psychologically safe are free to engage in risk-taking that is necessary for learning. Meanwhile, organizational climate refers to a common perception of company policy and procedure. The combination of the psychological safety and organizational climate factors produces the construct of psychological climate, which relates to a liberation from psychological and social risk in the workplace. Dollard (2010) predicted that the policies and practices, which secure 
worker safety and psychological well-being, would precede work context and would significantly predict both engagement and psychological health.

In support of Dollard's research, Hodges (2010) discovered that workers exhibited higher levels of engagement when employed in organizations that, in their opinion, possessed a positive psychological climate. Further, Lee and Ok (2015) also showed that if employees are to successfully engage, they must perceive the organizational environment as positive. More specifically, workers needed to believe that their company was customer-focused, that they received significant management support as they perform their work, and that the company offered convenient access to job-related information. The study also highlighted the importance of seamless cooperation between operational units and internal sharing of information. The researchers' conclusion was that management should foster and maintain a work environment that encourages dedication to customer service and provides abundant resources for its employees to strengthen engagement within the company. Likewise, as research by Kang and Busser (2018) explained, when employees' psychological needs are met, they are more predisposed to invest their time and effort as well as displaying increased levels of employee engagement.

As Kahn (1990) had revealed decades before, the greater the ability of the organization to provide a meaningful, safe, and resourceful environment for its employees, the more fertile the grounds for the growth of employee engagement and its beneficial outcomes. Therefore, organizations should prioritize the formation of a supportive culture where management and employees cooperate, communicate, and 
mutually commit to the achievement of corporate objectives for the benefit of the entire organization and its individual employees (Lee \& Ok, 2015).

Consistent with this previous research, the findings of this study showed that psychological climate had a significantly positive effect on employee engagement. The effect size was strong; a standard deviation increase in psychological climate was linked to a $79 S D$ increase in engagement. This supports the first hypotheses and validates the inclusion of psychological climate in the models of employee engagement presented in Chapter 1.

\section{Hypothesis 2}

The second hypothesis predicted a significant relationship between employee engagement and discretionary effort. First, the result of the correlational analysis illustrated a significantly positive relationship between employee engagement and discretionary effort. Second, the hierarchical regression results also demonstrated a powerful, positive link between the two variables after controlling for gender, ethnicity, job experience, job fit and psychological climate. These results offer support for $\mathrm{H} 2$; consequently, the null hypothesis was rejected.

The following section outlines the analysis of the relationship between employee engagement and the outcome variable of discretionary effort evaluated in the research. It will also define the study variable of discretionary effort.

Discretionary effort. Discretionary effort has been defined as the willingness to exert effort beyond the established requirements of a given organizational position 
necessary to avoid termination by supervisory personnel. According to Emde (1996), enhancements of discretionary effort are imperative to maximize an individual's contribution to the organization and to optimize organizational performance on a larger scale. Human resource professionals play a key role in the development of employee programs and alteration of work conditions within the organization which will promote an enhancement of discretionary effort levels of employees and departments (Psichogios, 2013).

In the current research, after controlling for gender, ethnicity, job experience, job fit, and psychological climate, employee engagement remained a strong predictor of discretionary effort among this sample of cruise line call center workers. A standard deviation increase in employee engagement corresponded to a $.50 S D$ increase in discretionary effort. The finding mirrors the results of a number of previous researchers.

Kahn's (1990) theoretical and empirical work, for instance, illustrated how employees who viewed their jobs as meaningful, felt adequately safe, and perceived that they were provided the necessary resources to perform their duties (the three main psychological components of employee engagement), tended to deliver levels of effort beyond the minimum expected. Lloyd's (2008) research, founded upon Kahn's theoretical and empirical work, also supported a positive link between engagement and increased effort (in this case discretionary effort). Likewise, the results of the present study demonstrated that employees who possessed higher levels of employee engagement tended to participate in more discretionary efforts related to performance of their job duties. Thus, this study not only supports Kahn and Lloyd's work, but also makes a new 
contribution to our understandings of the employee engagement-discretionary effort link because the effect remained strong, even after controlling for this unique combination of research variables (i.e., select demographic variables, job fit and psychological climate). Consequently, HR/D professionals and managers could benefit organizations by finding ways to promote employee engagement to enhance discretionary efforts among employees.

\section{Hypothesis 3}

The third hypothesis predicted a significant relationship between employee engagement and job performance. First, the result of the correlational analysis illustrated a significantly positive relationship between employee engagement and job performance. Moreover, the hierarchical regression results also demonstrated a positive effect on job performance after controlling for gender, ethnicity, job experience, job fit and psychological climate. These findings provide support for $\mathrm{H} 3$; the null hypothesis was rejected.

The following section outlines the analysis of the relationship between employee engagement and the outcome variable of job performance evaluated in the research. It will also define the study variable of job performance.

Job performance. Performance is a cornerstone of the field of HRD (Reio \& Wiswell, 2000; Shuck et al., 2017). HRD researchers and professionals seek ways to optimize employee performance for the good of the individual and organization. Performance carries a high degree of importance because it primarily determines disciplinary and reward actions of management. Job performance may be defined as the 
proficiency and accuracy with which the prescribed duties of a particular position are achieved by employees through specific actions and behaviors (Rotundo \& Sackett, 2002).

In this study, after controlling for select demographic variables (gender, ethnicity, job experience), job fit and psychological climate, employee engagement demonstrated a strong positive effect on job performance. A 1.0SD increase in employee engagement corresponded to a . $34 S D$ increase in job performance. These findings support the previous research of a number of scholars.

For example, a significant rise in overall employee performance was found to be a result of increased employee engagement in a large study of hospital workers (Wheeler et al., 2012). In addition, Lavigna (2015) showed that engaged employees displayed greater enthusiasm for their companies and job duties. As a result, they tended to exert themselves to perform above the minimum requirements of their positions, enabling them to be more proficient and increasingly competitive on individual levels. Additionally, Lavigna reported that companies that exhibited overall higher levels of employee engagement tended to be more productive and profitable as a result of this higher level of collective commitment and effort.

Earlier research by Gruman and Saks (2011) also detailed the importance of engagement in driving competitive advantage and desired outcomes for both individuals and organizations. In support of this, it was previously discovered by Demerouti, Cropanzano, Bakker, and Leiter (2010) that this relationship was largely facilitated by the 
increased relational psychological contract between employees, which they viewed as a precipitate of elevated employee engagement levels.

Additionally, in an Indian study of the nursing profession, Gupta and Aileen (2017) discovered that enhanced levels of employee engagement was positively linked to retention. This, in turn, was positively related to higher performance and productivity. Further, more in-depth analysis of the study data displayed a strong correlation between engagement and work team performance as well.

Job performance, standing as a well-supported outcome of employee engagement (e.g., Gupta \& Aileen, 2017; Lavigna, 2015; Wheeler et al., 2012), including the results of this research with a sample of call center workers from the cruise industry, is something then that might determine the success of both individual workers and entire organizations. Consequently, it is of vital importance. HRD researchers and practitioners, along with managers, are acutely aware of the need for optimized employee performance to attain and sustain competitive advantage (Ferguson \& Reio, 2010; Gruman \& Saks, 2011; Shuck et al., 2017). Finding additional evidence that employee engagement is a powerful predictor of job performance supports the need to target HRD-related activities that would foster greater engagement, such as increased access to training and development, career development and organizational development activities (e.g., coaching and mentoring, leadership development programs, etc.) (Shuck et al., 2017). Performance is the measuring stick by which the effectiveness of most company programs and projects are evaluated. Therefore, it is essential that organizations continue 
to formulate, implement, and continuously review their engagement enhancement efforts to support optimal employee performance and attaining competitive advantage.

\section{Implications for Theory, Research, and Practice}

Employee engagement has become a highly prioritized issue on the agendas of HR/D managers in recent decades (Huang, Ma, \& Meng, 2018), while also becoming a significant topic of interest for human resource scholars (Macey \& Schneider, 2008; Shuck et al, 2017). This research has demonstrated the importance of employee engagement as an important organizational precursor to discretionary effort and job performance, both of which have been demonstrated to be linked to higher levels of productivity and profitability (Harter et al., 2002). The following sections explore the implications of this research to theory building, research, and practice in the HRD field.

\section{Implications for Theory}

The engagement models presented in the study focused on certain significant antecedents and outcomes which the researcher perceived to be of greatest importance to the cruise line call center workplace. The research results builds upon existing empirical studies and offers further support for the employee engagement model originally configured by Kahn (1990) through the presentation of the correlational relationships between the variables. Specifically, the current research determined that after controlling for the select demographic variables, job fit and psychological climate were positively linked to employee engagement, which, in turn, played a salient role in the enhancement of discretionary effort and job performance. This finding further supports the previously stated theory that an engaged workforce can have a profound influence on discretionary 
effort and employee job performance. Highly engaged workers exhibit a passion for their job duties while possessing an emotional connection to their respective firms.

Alternately, disengaged employees offer their time, but not substantial energy or attention into their work (Bal, Dorien, \& De Jong 2013). Engaged employees also display more creativity, are more likely to perform better, and frequently develop and proliferate sustainable competitive advantages for their organizations (Huang et al., 2018).

The models and results presented support Kahn's (1990) engagement theory, as the results advance the overall theoretical understanding of employee engagement while providing for a specific contextual understanding of the dynamics of engagement within the hospitality call center niche. Employee engagement was strongly linked to both discretionary effort and job performance as Kahn's engagement theory predicted, but in the hospitality industry; therefore, a new test for his theory. Hospitality firms, then, might benefit from studying and embracing the concept and formulation of additional engagement enhancement paradigms for employees. Given the lack of published research directly pertaining to employee engagement in the hospitality call center environment, this study will add substantially to what hospitality HRD professionals can access in terms of relevant research to guide the understanding and application of the concept of engagement as it relates to the call center workplace.

\section{Implications for Research}

It is important for researchers to continue building on published employee engagement research while continuing to test the two engagement models presented in this research, and variations of it (e.g., by adding theoretically relevant variables like 
workplace incivility, risk taking, creativity, personality traits; see Reio \& Sanders-Reio, 2011; Shuck et al., 2017) in a variety of contexts. The antecedent and outcome variables should be examined individually across these contexts to determine the sources and influences that produce variations across different organizational environments and occupations. The study of employee engagement across diverse settings and populations will facilitate knowledge acquisition and more nuanced understandings of engagement that will facilitate theory building and its practical applications in workplace settings locally, nationally, regionally, and internationally.

Longitudinal research of employee engagement should also be performed as a means of gaining knowledge of how time can affect levels of employee engagement within individual workers, teams, and organizations. Research studies could focus on specific individuals or work teams (e.g., cross-functional) within companies of different industrial affiliations over a variety of specific time periods. The researchers could then measure fluctuations of individuals', teams', companies', and industries' employee engagement levels over specific time periods and cycles (Shuck et al., 2011).

To gain the best possible perspective of how engagement correlates to certain other variables within a specific organization or industry, the study should be designed to collect data at a certain workplace or industrial genre. This would provide for a more accurate and reliable reflection of psychological factors and variables at work within a common range of locations or duties. For example, the single case study design described by Yin (2003) offers a means of achieving the purpose of gaining a focused analysis of research variables in a selected workplace. Additionally, qualitative research 
can be employed to gain a detailed introspection of employee attitudinal behaviors by allowing them to express themselves in detailed interviews rather than a structured survey. This gives researchers the ability to collect more personalized and comprehensive data regarding the variables of interest and their respective relationships. This would serve to broaden the scope of understanding in terms of employee engagement by allowing employees to expand on their individual responses to each survey item presented as a means of enhancing external validity and depth of knowledge regarding the study variables (Shuck et al., 2011).

This study should also produce further research on employee engagement and job performance in the call center workplace given the current lack of available published studies and associated data. While hospitality HR/D practitioners continue to seek new means of understanding engagement and its relationships to motivators and psychological variables within their firms, there is not a reliable, tested hospitality call center employee engagement enhancement guide to follow. This research could stimulate follow-up studies that may further the comprehension of the variables involved as well as guidance to formulate interventions that would elevate engagement levels and performance in their respective workplaces. Given the frequently heavy utilization of call centers in the cruise line business as well as other hospitality sectors such as land tour companies, airlines, hotel chains, car rental firms, and travel agencies, it is imperative that the industry has validated research and analysis at its disposal to refer to for designing employee engagement interventions. Currently, hospitality practitioners must depend on research performed within other industries that, in some cases, can be vastly different in relation to personnel, management, and products. This creates a situation where HR/D management 
must attempt to retrofit studies and interventions from other industries which may suffer from a lack of applicability to the employees in the hospitality genre. The result is a less than optimally effective employee engagement regime which might fall short of providing expected outcomes.

An example of this would be to attempt to use an employee engagement study conducted at an automotive assembly plant to try to further performance in an airline reservation call center. An obvious barrier to an effective utilization of the study and any interventions developed from it is that there could be a completely different employee base, both demographically and psychologically. As a result, the comprehension of the relationships between employee engagement and its antecedents and outcomes for an automotive assembly worker might not significantly relate to that for a call center employee. This is a reason why more employee engagement studies are required for the hospitality call center environment if HR/D practitioners are to make the best use of employee engagement theory in formulating training and motivational paradigms within their organizations. As engagement research becomes more plentiful, relevant, and reliable, researchers will gain credibility and be more frequently called upon for their consultative input.

\section{Implications for Practice}

As stated in the previous sections, this research begins to the fill the void that currently exists of published research that directly addresses engagement and its concomitant outcomes in the hospitality call center workplace. Using this study as well as other research that will be stimulated as a result, hospitality HR/D practitioners can 
begin to formulate improved employee engagement enhancement programs with their employees which will address the typical psychological and demographic profiles of their employees. Having directly relevant research will allow them to design engagement programs which will address common issues within their hospitality organizations in more efficient and effective ways. This relevance will stand to bolster and further the growth of both the employee engagement topic among scholars and the devotion to engagement theory of hospitality management professionals.

Organizations and researchers have already witnessed the importance of employee engagement to the well-being and productivity to their workplaces for the previous two decades (Dalal et al., 2012; Demerouti et al., 2001; Kahn, 1990), but require advancement and specialization of engagement research to continue developing and engraining employee engagement within their organizations. As companies continue to grow and increase in complexity, the burden on workers to adjust to changes in the workplace increases, thereby requiring greater levels of employee engagement to allow them to maintain their vigor and focus throughout periods of organizational flux and transition. Engagement allows workers to remain psychologically synchronized with the objectives of the company through corporate growth and adjustment processes, providing them the continued ability to perform under pressure and at optimal levels of productivity (Bakker \& Demerouti, 2008).

The first step in designing improved employee conditioning programs is to begin at the root of what has been shown in this study to drive elevated engagement, the 
antecedents of job fit and organizational climate. These are the precursors that combine to create enhanced employee engagement levels.

By accurately defining the psychological, intellectual, and skill-based requirements of a position, then matching those criteria with the personal attributes of employees, the intent of the job fit variable is realized. Job fit has been shown to significantly correlate with employee engagement in a wide variety of research studies in recent years (Biswas \& Bhatnagar, 2013; Chen et al., 2014; Kristof-Brown, 2016) by providing workers a job with duties and objectives that are challenging, meaningful, and attainable, employees can better align with organizational goals and feel more emotionally attached to their positions.

Psychological climate is the other antecedent to engagement highlighted and examined in this study. Employees who feel at ease to "be themselves' at work, perceive that they are personally and professionally supported by their peers, and are being provided the necessary resources within a supportive job environment will tend to feel increasingly motivated by and engaged with their organization (Kahn, 1990). If HR/D professionals and line managers alike can provide a formative environment where an employee can feel comfortable with both colleagues and the physical office surroundings, they will likely benefit from greater employee engagement.

Therefore, hospitality HR/D managers should take heed of these research results to better design workplaces and train both ownership and management to raise awareness of what is required to increase engagement through the variables of job fit and organizational climate. Metaphorically speaking, strengthening the antecedent roots (job 
fit and psychological climate) within the firm will allow the plant (employee engagement) to bear greater volumes of fruit (discretionary effort and performance).

Additionally, management practitioners can utilize this study to gain knowledge of discretionary effort. As stated in this study, increasing employees' vigor and emotional attachment to their respective organizations and objectives can influence their willingness to deliver increased levels of effort and the desire to achieve beyond what is minimally required to remain employed. This emphasizes the importance of engagement by providing management empirical evidence of its benefits to the company. As a result, HR/D managers will be able to design and evaluate engagement innovations and interventions by gauging the effect on the workforce in terms of effort expended, willingness to work overtime to complete projects, and eagerness to perform.

Job performance may be considered a priority in the workplace given the direct impact that reservation workers' productivity has on cruise lines' ability to fill ships to capacity and optimize bottom-line results. This research is useful for management practitioners who have needed to generalize engagement studies from other industries into the hospitality call center genre. Engagement research from other industries may not take into consideration the unique characteristics and demographics of typical call center employees or distinctive characteristics of the call center environment that can influence engagement levels and organizational outcomes.

\section{Limitations of the Study}

As with any research, the research described here comes along with some possible limitations. The first limitation was the utilization of convenience sampling in gaining 
data from two particular cruise line companies that were most accessible to the researcher. While these organizations represent a significant cross-section of the industry, there are other firms with various geographic and demographic differences that were not represented. Therefore, we must consider that the sample of participants utilized may not be flawlessly representative of the nationwide or world-wide cruise line employee population. While the use of convenience samples tends to be common in organizational and HRD research, (e.g., Pabón \& Reio, 2018; Shuck et al., 2017), efforts to generalize beyond the current study's results to samples of workers outside the U.S. service industry should only be done cautiously (Tabachnick \& Fidell, 2001).

The second limitation is the use of self-report measures for this study (Reio, 2010). HRD researchers point to the benefits of using self-reports that includes ease of administration, quick turnaround for data collection and low relative cost. Yet, using selfreports, which in the case of this research is a single source of data, may be linked to introducing common method variance bias (CMV) into the study because it may systematically increase or decrease correlations among the research variables (Reio). To reduce the likelihood of introducing CMV into the study, the researcher employed three procedural steps. First, validated research measures were used, except for job performance which was designed specifically for cruise line workers. Second, a pilot study was conducted to assure that the directions and items themselves were unambiguous and that the items represented the constructs in question (content validity). Finally, participant anonymity was assured (Podsakoff et al., 2003). 
A third possible limitation is that participants may under- or over-report their level of engagement, discretionary effort and job performance. This social desirability issue is relatively common in organizational research but has not been noted by HR/D researchers as being particularly problematic with these three variables (Reio, 2010; Shuck et al., 2017). Still, the results should be interpreted cautiously with this possible caveat in mind.

Another possible limitation, as with any survey study, was the response rate. Without $100 \%$ participation, it is possible that those who completed the survey battery would be, in some manner, systematically different from those who did not. Because were not privy to the precise number of call workers at each site, we were not able to calculate the response rates for this study. Again, this suggests that the results should be interpreted prudently.

\section{Conclusion}

This research study examined the relationships between job fit, organizational climate, and employee engagement, and discretionary effort and job performance. The results of the research supported the proposed engagement models. Future studies related to these antecedents and outcomes of employee engagement can build on these findings to further evaluate employee engagement and its potential benefits to organizations. Meanwhile, organizations can utilize the results of this study to more deeply comprehend how employee engagement is an essential precursor to discretionary effort and job performance that may be enhanced and engrained within their employee ranks through 
improved corporate hiring, training, management, and organizational socialization processes.

Both organizational scholars and hospitality practitioners should embrace the meaning and the potential value of this addition to employee engagement research. It offers both a look at employee engagement as it relates to the cruise line/ hospitality industry and simultaneously provokes thought and provides a guide to better management and employee engagement within relevant businesses.

This study will hopefully serve as inspiration for further employee engagement studies pertinent to the hospitality industry being there is so little research currently. This study can also act as a launch point for further examination of employee engagement and motivation within the customer contact center business genre, which stands as another area that has a relative void of published research for employees and management practitioners to reference. Given the increasing popularity and utilization of customer service contact centers, it is important that scholars increase their level of research activity in this area to assist practitioners in the growth and successful operation of such entities. With customer service standing as a priority for so many hospitality-related businesses, it is essential that better management and employee performance solutions be developed to improve not only the satisfaction of organizational ownership seeking and management seeking increased profitability, but also of the customers who interface with the contact center employees when in search of product and service offerings. As previously explained, the greater the success of cruise lines in attracting guests, the 
greater the financial benefits for businesses and communities within the vicinity of cruise line ports. 


\section{REFERENCES}

Albrecht, S. (2012). The influence of job, team and organizational level resources on employee well-being, engagement, commitment and extra-role performance. International Journal of Manpower, 33, 840-853.

Anand, N. (2011). New technologies, work, skills, and identity: The case of maritime Industry, Cardiff University.

Bakker, A., \& Leiter, M. (2010). Work engagement: A handbook of essential theory and research. New York: Psychology Press.

Baltes, B. (2001). Psychological climate in the work setting. International encyclopedia of the social \& behavioral sciences. Retrieved from thttp://www.sciencedirect.com/science/article/pii/B0080430767014376).

Bandura, A. (1993). Perceived self-efficacy in cognitive development and functioning. Educational Psychologist, 28, 117-148.

Bates, S. (2004). Getting engaged. HR Magazine, 49(2), 44-51.

Biswas, S. \& Bhatnagar, J. (2013). Mediator analysis of employee engagement: Role of perceived organizational support, P-O fit, organizational commitment and job satisfaction. The Journal for Decision Makers, 38, 27-40.

Blank, P. (2012). Employee engagement: Lessons from the mouse hotel. United States: Pete Blank.

Bowen, D., Siehl, C. \& Schneider, B. (1989). A framework for analyzing customer service orientations in manufacturing. The Academy of Management Review, 14, 75-95.

Breevaart, K., Bakker, A., \& Demerouti, E. (2014). Daily self-management and work engagement. Journal of Vocational Behavior, 84, 31-38.

Burke, R. J., Koyuncu, M., Jing, W., \& Fiksenbaum, L. (2009). Work engagement among among hotel managers in Beijing, China: Potential antecedents and consequences Tourism Review, 64(3), 4-18.

Byrne, Z. S. (2015). Understanding employee engagement: Theory, research, and practice. New York: Routledge, Taylor \& Francis Group.

Chen, C. Y., Yen, C. H., \& Tsai, F. C. (2014). Job crafting and job engagement: The mediating role of person-job fit. International Journal of Hospitality Management, 37, 21-28. 
Chowdhury, M. (2008). Enhancing motivation and work performance of the Salespeople: The impact of supervisors' behavior. The International Journal of Applied Management and Technology, 6, 238-243.

Cohen, J. (1988). Statistical power analysis for the behavioral sciences. San Diego, CA: Academic Press.

Cronbach, L. (1950). Statistical methods for multi-score tests. Journal of Clinical Psychology, 6, 21-26.

Dalal, R., Baysinger, M., Brummel, B., \& LeBreton, J. (2012). The relative importance of employee engagement, other job attitudes, and trait effect as predictors of job performance. Journal of Applied Social Psychology, 42, 295-325.

Daniels, A. (2013). Discretionary effort. Retrieved from http://aubreydaniels.com/discretionary-effort.

Demerouti, E., Cropanzano, R., Bakker, A. \& Leiter, M. (2010). From thought to action: Employee work engagement and job performance. Work engagement: $A$ handbook of essential theory and research (pp. 147-163). Psychology Press: Hove, East Sussex, UK.

Dollard, M. (2010). Psychological safety climate as a precursor to conducive work environments, psychological health problems, and employee engagement. Journal of Occupational and Organizational Psychology, 83, 579-599.

Dillman, D. A., Smyth, J. D., \& Christian, L. M. (2009). Internet, mail, and mixed-mode survey: The tailored design method. Hoboken, NJ: John Wiley \& Sons.

Dillman, D. A., Tortora, R. D., \& Bowker, D. K. (1999). Principles for constructing web surveys. Retrieved: http://survey.sesrc.wsu.edu/dillman/papers/websurveyppr.pdf

Elsley, N. (2009). Canon triggers employee self-discovery strategy. Training and Development in Australia, 36, 12-15.

Emde, E. (1996). Discretionary effort. Executive Excellence, 13(12), 18.

European Agency for Safety and Health at Work (2002). Systems and programmes: How to tackle psychosocial issues and reduce work-related stress. Luxembourg: Office for the Publications of the European Communities.

Ferguson, K., \& Reio, T. G., Jr. (2010). Human resource management systems and firm performance. Journal of Management Development, 29, 471-494. 
Frankel, S., Restubog, S. L. D., \& Bednall, T. (2012). How employee perceptions of HR policy and practice influence discretionary work effort and co-worker assistance: Evidence from two organizations. The International Journal of Human Resource Management, 23, 4193-4210.

Garcia-Buades, E., Martinez-Tur, V., Ortiz-Bonnin, S., \& Peiro, J. (2016). Engaged teams deliver better service performance in innovation climates. European Journal of Work and Organizational Psychology, 25, 597-623.

Garner, B., \& Hunter, B. (2013). Examining the temporal relationship between psychological climate, work attitude, and staff turnover. Journal of Substance Abuse Treatment, 44, 193-200.

Gelman, A. (2007). Data analysis using regression and multilevel/ hierarchical models. New York: Cambridge University Press.

Greenleaf, R. K. (1998). The power of servant leadership. San Francisco: Berrett Koehler.

Gruman, J. \& Saks, A. (2011). Performance management and employee engagement. Human Resource Management Review, 21, 123-136.

Gulliksen, V. (2008). The cruise industry. Society, 45, 342-344.

Gupta, M., \& Aileen, J. (2017). Development of employee engagement model in a tertiary care hospital. International Journal of Nursing Education, 9, 77-82.

Hackman, J. \& Oldham, G. (1976). Motivation through the design of work: Test of a theory. Organizational behavior and Human Performance, 16, 250-279.

Hallberg, U. E., Johansson, G., Schaufeli, W. B. (2007). Type A behavior and work situation: Association with burnout and work engagement. Scandinavian Journal of Work, Environment, and Health, 48(25), 135-142.

Harter, J, Schmidt, F. \& Hayes, T. (2002). Business unit-level relationship between satisfaction, employee engagement, and business outcomes: A meta-analysis. Journal of Applied Psychology, 87, 268-279.

Hauser, L. (2014). Work motivation in organizational behavior. Economics, Management, and Financial Markets, 9, 239-246.

Hayes, A. F. (2012). PROCESS: A versatile computational tool for observed variable mediation, moderation, and conditional process modeling [White paper]. Retrieved from http://www.afhayes.com/public/process2012.pdf. 
Heiervang, E., \& Goodman, R. (2011). Advantages and limitations of web-based surveys: Evidence from a child mental health survey. Social Psychiatric Epidemiology, $46,69-76$.

Hinkin, T. (1995). A review of scale development practices in the study of organizations. Journal of Management, 21, 967-988.

Hodges (2010). An experimental study of the impact of psychological capital on performance, engagement, and the contagion effect. Retrieved from the University of Nebraska- Lincoln Digital Commons.

Howard, L. W., \& Foster, S. T. (2009). The influence of human resource practices on Empowerment: An employee perception of management commitment to quality. Journal of Quality Management, 4, 5-22.

Huang, Y., Ma, Z., \& Meng, Y. (2018). High-performance work systems and employee engagement: Empirical evidence from China. Asia Pacific Journal of Human Resources, 56, 341-359.

Hui, C., Wong, A., \& Tjosvold, D. (2007). Turnover intention and performance in China: Theory of positive affectivity, Chinese values, perceived organizational support, and constructive controversy. Journal of Occupational and Organizational Psychology, 80, 735-751.

Ishfaq, A. (2010). Effects of motivational factors on employees' job satisfaction. International Journal of Business Management, 5, 295-304.

Jacobs, H. (2013). An examination of psychological meaningfulness, safety, and availability as the underlying mechanisms linking job features and personal characteristics to work engagement (Doctoral dissertation). Retrieved from FIU Electronic Theses and Dissertations. (904).

Johnson, B. (2001). Toward a new classification of nonexperimental quantitative research. Educational Researcher, 30, 3-13.

Kahn, W. (1990). Psychological condition of engagement and disengagement at work. Academy of Management Journal. 23, 692-723.

Kang, H. \& Busser, J. (2018). Impact of service climate and psychological capital on employee engagement: The role of organizational hierarchy. International Journal of Hospitality Management, 75, 1-9.

Kim, W., Kolb, J. A., \& Kim, T. (2013). The relationship between work engagement and performance: A review of empirical literature and a proposed research agenda. Human Resource Development Review, 12, 248-276. 
Kim, H., Shin, K., \& Swanger, N. (2009) Burnout and engagement: A comparative analysis using the big five personality dimension. International Journal of Hospitality Management, 28, 96-104.

Kristoff-Brown, A. L. (2014). Person-job fit. Encyclopedia of industrial and organizational psychology. http://dx.doi.org/10.4135/9781412952651.n236.

Laschinger, S. \& Finegan, J.(2005). Empowering nurses for work engagement and health in hospital settings. Journal of Nursing Administration, 35, 439-449.

Lavigna, B. (2015). Why employee engagement matters and why engagement efforts fail. Government Finance Review, 31, 32-38.

Lee, J. \& Ok, C. (2015). Drivers of work engagement: An examination of core selfevaluations and psychological climate among hotel employees. International Journal of Hospitality Management, 44, 84-98.

Lloyd, R. (2008). Discretionary effort and the performance domain. New England Journal of Organisational Psychology, 1, 22-34.

Macey, W. H., \& Schneider, B. (2008). The meaning of employee engagement. Industrial and Organizational Psychology, 1, 3-30.

Macey, W. H., Schneider, B. Barbera, K. \& Young, S. (2009). Employee engagement: Tools for analysis, practice, and competitive advantage. Wiley-Blackwell and Malden, MA.

Markos, S. (2010). Employee engagement: The key to improving performance. International Journal of Business and Management, 5(12), 89-96.

May, D., Gilson, R., \& Harter, L. (2004). The psychological conditions of meaningfulness safety, and availability and the engagement of the human spirit at Journal of Occupational and Organizational Psychology, 77, 11-37.

Mone, E., \& London, M. (2010). Employee engagement through effective performance management. New York: Routledge, Taylor \& Francis Group.

Moreland, J. (2013). Improving job fit can improve employee engagement and. productivity. Employee Relations Today, 40, 57-62.

Offstein, E. H., Gnyawali, D. R., \& Cobb, A. T. (2005). A strategic human resource perspective of firm competitive behavior. Human Resource Management Review, $15,305-318$. 
Pabón, L. C., \& Reio, T. G., Jr. (2018). The relationship between engagement and knowledge attainment in a computer-based training game and job performance of travel agents. Journal of Management Development, 37, 452-469.

Pam, M. (2016). What is an antecedent variable? Retrieved from http://www. psychologydictionary.org.

Parsa, H., Tesone, D., \& Templeton, A. (2009) All employees are not created equal: An alternative method of assessing employee turnover. Journal of Foodservice Business Research, 12, 317-330.

Pitt-Catsouphes, M., Matz-Costa, C. (2008) The multi-generational workforce: Workplace flexibility and engagement. Community, Work, \& Family, 11, 215-229.

Psichogios, P. (2013). Aim for exceptional employee experiences: Sustained employee engagement results from maintaining positive experiences in the workplace. $T+D, 67(6), 34-35$.

Rada, V., Diaz, V., \& Dominguez-Alvarez, J. (2014). Response quality of selfadministered questionnaires: A comparison between paper and web questionnaires. Social Science Computer Review, 32, 256-269.

Radic, I. (2015). International Conference: Employment relations - Development and challenges. Zagreb Law Review, 4, 261-267.

Reio, T. G., Jr. (2010). The threat of common method variance bias in theory building. Human Resource Development Review, 9, 405-411.

Reio, T. G., Jr., \& Wiswell, A. (2000). Field investigation of the relationship between adult curiosity, workplace learning, and job performance. Human Resource Development Quarterly, 11, 1-36.

Reio, T, G., Jr., \& Sanders-Reio, J. (2011). Thinking about workplace engagement: Does supervisor and coworker incivility really matter? Advances in Developing Human Resources, 13, 462-478.

Reno, K. (2013). Engagement in virtual communities of practice in professional interest associations: The role of discretionary effort, emotional connectedness and Retrieve from ProQuest Dissertations and Theses.

Resnick, M. (2009). Safety incentive programs. Professional Safety, 54(7), 46-48. 
Rigg, J., Sydnor, S., Nicely, A., \& Day, J. (2014) Employee engagement in Jamaican hotels: Do demographic and organizational characteristics matter? Journal of Human Resources in Hospitality and Tourism, 13, 1-16.

Risitano, M., Sorrentino, A., \& Quintano, M. (2017). Understanding the role of the Service experience in the cruise industry. International Journal of Tourism Policy, 7, 289-30.

Rofcanin, Y, \& Mehcap, O. (2010). Implications of leader-member exchange relationship theory and transformational leadership dimensions on subordinate citizenship behavior: An empirical paper from Turkey with services industry focus. International Journal of Global Business, 3, 83-101.

Rotundo, M. \& Sackett, P. (2002). The relative importance of task, citizenship, and counterproductive performance to global ratings of job performance: a policy capturing approach. Journal of Applied Psychology, 87, 66-80.

Saks, A., \& Ashforth, B. (1997). A longitudinal investigation of the relationships between job information sources, applicant perceptions of fit, and job outcomes. Personnel Psychology, 50, 395-426.

Saks, A. M., \& Gruman, J. A. (2014). What do we really know about employee engagement? Human Resource Development Quarterly, 25, 155-182.

Schaufeli, W., Bakker, A., \& Schaufeli, W., Bakker, A., \& Salanova, M. (2006). The measurement of work with a short questionnaire. Educational and Psychological Measurement, 66, 701-716.

Schermerhorn, J. R. (2010). Introduction to management. Upper Saddle River, NJ: John Wiley \& Sons, Inc.

Salanova, M. (2006). The measurement of work with a short questionnaire. Educational and Psychological Measurement, 66, 701-716.

Shuck, B. (2010). Employee engagement: An examination of antecedent and outcome variables. Retrieved from FIU Electronic Theses and Dissertations. (235).

Shuck, B., Adelson, J., \& Reio, T. G., Jr. (2017). The Employee Engagement Scale: Initial evidence for construct validity and implications for theory and practice. Human Resource Management, 56, 953-977.

Shuck, B., Reio, T., \& Rocco, T. (2011). Employee engagement: An examination of antecedent and outcome variables. Human Resource Development International, 14, 427-445. 
Shuck, B., Rocco, T., \& Albornoz, C. (2011). Exploring employee engagement from the employee perspective: Implications for HRD. Journal of European Industrial Training, 35, 300-326.

Shuck, B., Twyford, D., Reio, T. G., Jr., \& Shuck, A. (2014). Human resource development practices and employee engagement: Examining the connection with turnover intentions. Human Resource Development Quarterly, 25, 239-270.

Smith, G. (2004). An evaluation of the corporate culture of Southwest Airlines. Measuring Business Excellence, 8, 26-33.

Stone, D. N., Deci, E. L., \& Ryan, M. R. (2009). Beyond talk: Creating autonomous through self-determination theory. Journal of General Management, 34, $75-91$.

Thomas, M. (2015). Strategic principles at Southwest Airlines. Strategic Direction, $31(8), 10-12$.

Thompson, B. C., \& Panacek, E. (2007). Research study designs: Nonexperimental. Air Medical Journal, 26, 18-22.

Truss, C., Delbridge, R., Alfes, K., Shantz, A., \& Soane, E. (2014). Employee engagement in theory and practice. New York: Routledge.

Van Den Broeck, A., Vansteenkiste, M., De Witte, H., \& Lens, W. (2008). Explaining the relationship between job characteristics, burnout, and engagement: The role of basic psychological need satisfaction. Work and Stress, 22, 277-294.

Wanous, J. P., \& Reichers, A. E. (1996). Estimating the reliability of a single-item measure. Psychological Reports, 78, 631-634.

Walker, S. (2012). Employee engagement and communication research. Philadelphia: Kogan Page Limited.

Wheeler, A., Harris, J. \& Sablynski, C. (2012). How do employees invest abundant resources? The mediating role of work effort in the job-embeddedness/ job-performance relationship. Journal of Applied Social Psychology, 42, E244E266.

Williams, W. \& Seiler, D. (1973). Relationship between measures of effort and job performance. Journal of Applied Psychology, 57, 49-54.

Yalabik, Z., Popaitoon, P., Chowne, J., \& Rayton, B. (2013). Work engagement as a mediator between employee attitudes and outcomes. International Journal of Human Resource Management, 24, 2799-2823. 
Yin, R. (2003). Case study research: Design and methods (3rd ed.), London: Sage.

Zeng, H., Zhou, X. \& Han, J. (2009). Employee engagement and personal performance hotel service industry in China. 6th International Conference on service systems 


\section{Appendix A}

Please use the scale below to answer the following questions:

$1=$ Strongly Disagree

$2=$ Disagree

$3=$ Neutral.

4= Agree

5= Strongly Agree

1. I know what is expected of me at work.

2. I have the materials and equipment I need to do my work right.

3. At work, I have the opportunity to do what I do best every day.

4. In the last seven days, I have received recognition or praise for doing good work.

5. My supervisor, or someone at work, seems to care about me as a person.

6. At work, my opinions seem to count.

7. The mission of my company makes me feel my job is important.

8. My knowledge, skills, and abilities "match" or fit the requirements of the job.

9. At work, I have the opportunity to do what I do best every day. 
10. I have a best friend at work.

11. I do more than is expected of me.

12. I take my job seriously and rarely make mistakes.

13. I try hard to increase my skills to improve the quality of my work.

14: I am really focused on my job when I am working.

15: I concentrate on my job when at work.

16: When at work, I think a lot about how to be my best.

17: At work, I am focused on my job.

18: Working at my current organization has a great deal of personal meaning to me.

19: I feel a strong sense of belonging to my job.

20: I am proud to tell others that I work for my current company.

21: I believe in the mission and purpose of my company.

22: I really push myself to work beyond what is expected of me.

23: I am willing to put in extra effort without being asked.

24: I often go beyond what is expected of me to help my team be successful.

25: I work harder than expected to help my company be successful.

26. My average monthly booking production exceeds goals set by management.

27. I consistently produce more monthly bookings than my colleagues. 
Demographics:

1: Please disclose your ethnic background:

1) White

2) Black

3) Hispanic

4) Asian

5) Other.

6) I choose not to answer.

2: What is your age group?

1) $18-25$

2) $\quad 26-36$

3) $\quad 37-47$

4) 48-59

5) $60+$

6) I choose not to answer.

3: Please state your highest level of completed education:

1) High school

2) Junior College (2 yr.) 
3) College (4 yr.)

4) Master's degree

5) PhD, Ed.D., J.D., M.D. D.D.S.

6) I choose not to answer.

4: Please state your level of experience at your current job:

1) Less than 1 year.

2) 1 to 2 years.

3) 2 to 5 years.

4) 5 to 10 years.

5) More than 10 years.

6) I choose not to answer.

5: Please state your gender:

1) Male.

2) Female.

3) I choose not to answer. 
VITA

\section{STEPHEN BERNARD RODOQUINO III}

Place of Birth

1986

1986-1987

1987-1988

1989-1994

1995-1996

1996-2001

2003-2011

2012

2012-2014

2015

2015-present

2015-2016

2016-2017
Elizabeth, New Jersey

Bachelor of Science in Business Administration

Montclair State University, Upper Montclair, New Jersey

Assistant Store Manager

CVS Pharmacy, North Arlington, New Jersey

Master of Business Administration Studies

University of Miami, Coral Gables, Florida

International Sales Manager

AT\&T, Fort Lauderdale, Florida

Territory Sales Manager

G.E. Capital Assurance, Miami, Florida

Sales Coach

Renaissance Cruises, Fort Lauderdale, Florida

President

The International Traveler, Inc., Aventura, Florida

Master of Science in Hospitality Management Florida International University, Miami, Florida

President

Asian Journeys Corp., Iselin, New Jersey

Master of Arts in Asian Studies

Florida International University, Miami, Florida

Doctoral Candidate

Florida International University, Miami, Florida

Financial Professional

New York Life, Sunrise, Florida

Financial Professional

Prudential Financial, Boca Raton, Florida 
President

SBR International, Aventura, Florida 